\title{
Epigenética y gestación por sustitución: más razones a favor de una regulación internacional para un negocio global*
}

\section{Epigenetics and Commercial Surrogacy: More Reasons For International Law Regulting this Global Business}

\section{Daniel García San José ${ }^{* *}$}

\begin{abstract}
SUMARIO: I. Introducción: objetivos, metodología y justificación de la sistemática seguida. II. El debate ético-económico en la gestación por sustitución como condicionante previo para un debate jurídico sobre la cuestión. III. Eventual incidencia de la epigenética en la gestación por sustitución. IV. En defensa de una regulación internacional de la gestación por sustitución a partir de la necesaria consideración de los riesgos epigenéticos para los derechos fundamentales en juego. V. A modo de inspiración para el legislador internacional: un instrumento convencional de protección de los derechos humanos ad hoc para la gestación por sustitución que tome en consideración todos los intereses en juego a partir de la experiencia del tribunal europeo de derechos humanos. VI. A modo de conclusiones provisionales.

VII. Bibliografía.
\end{abstract}

\footnotetext{
* Este trabajo recoge una investigación financiada con fondos públicos: "Epigenética: nuevos desafíos para los derechos fundamentales en el ordenamiento internacional, europeo y nacional”. Proyecto de excelencia financiado por el Ministerio de Economía y Competitividad del Reino de España en su convocatoria RETOS de 2015 (DER2015-64151-R), del que soy investigador principal.

** Universidad de Sevilla. E-mail: dagarcia@us.es.
} 
RESUMEN: Este trabajo se centra en el interés superior del menor frente a los riesgos epigenéticos derivados de los contratos de gestación por sustitución. Se defiende la necesidad de contar con un convenio de protección de derechos humanos ad hoc para la gestación por sustitución. Dicho Convenio debería inspirarse en la teoría del justo equilibrio de los distintos intereses en juego, como viene desarrollando el Tribunal Europeo de Derechos Humanos en casos recientes: Labasse y Menesson con Francia y Paradiso y Campanelli contra Italia. Aun cuando las cuestiones epigenéticas no se plantean en dicha jurisprudencia su invocación responde al deseo de que el interés superior del menor sea considerado en relación con su derecho a la identidad como parte de su vida privada, como hasta ahora, pero, además, en atención a la efectiva protección de su derecho a la salud.

Palabras clave: interés superior del menor, contratos de gestación por sustitución, implicaciones éticas y legales de la epigenética, teoría del justo equilibrio de los distintos intereses en juego.

ABSTRACT: The analysis here developed focuses on the examination of the epigenetic risks for the health of children born through commercial surrogacy. It is defended the urgent need for an International Convention on human rights ad hoc for gestation by commercial surrogacy. To this aim we propose as inspiration for international legislator the theory of the right balance of different interests at stake, as it has been developed for decades by the European Court of Human Rights: Labasse and Menesson against France and Paradiso and Campanelli against Italy. Whereas epigenetics are not invoked in those judgments we consider relevant for our analysis as we defend that the superior interest of the child should be considered as regards the right to personal identity under the right to private life, as it is presently, but also linked to the right to health of children born through gestation by commercial surrogacy.

Key words: best interest of the minor, commercial surrogacy arrangements, legal and ethical implications of epigenetics, theory of fair balance of interests at stake.

RÉSUMÉ: L'intérêt supérieur de l'enfant face aux risques épigénétiques encourus dans le cas de contrats de gestation pour autrui constitue le thème central du présent travail. Nous estimons qu'une Convention de protection des droits individuels de la personne ad hoc est nécessaire pour la gestation pour autrui. Une telle Convention devrait s'inspirer de la théorie du juste équilibre entre les divers intérêts en jeu à l'image de la Cour européenne des droits de l'homme: affaire Labassé et Mennesson contre la France et affaire Paradiso et Campanelli contre l'Italie. Même lorsque les questions épigénétiques ne sont pas abordées dans telle ou telle jurisprudence, le fait d'en parler permet d'espérer que l'intérêt supérieur de l'enfant soit un jour envisagé en relation avec son droit à l'identité en tant qu'élément essentiel de sa vie privée, comme jusqu'à maintenant, mais en prenant également en compte son droit à la santé avec une protection efficace dans ce domaine.

Mots-clés: intérêt supérieur de l'enfant, contrats de gestation pour autrui, implications éthiques et juridiques de l'épigénétique, théorie du juste équilibre entre les divers intérêts en jeu. 
Esta revista forma parte del acervo de la Biblioteca Jurídica Virtual del Instituto de Investigaciones Jurídicas de la UNAM

\section{INTRODUCCIÓN: OBJETIVOS, METODOLOGÍA \\ Y JUSTIFICACIÓN DE LA SISTEMÁTICA SEGUIDA}

En la actualidad, la regulación a nivel nacional de la gestación por sustitución es, sin duda, una fuente de inseguridad jurídica por cuanto puede calificarse de geometría variable: los Estados prohíben o permiten ésta libremente, tanto si es altruista como onerosa, y entre aquellos Estados que la prohíben, algunos reconocen sus efectos jurídicos cuando es practicada en un Estado que sí la tolera, mientras que otros no los reconocen. Ante la inexistente regulación internacional en la materia, mi primer objetivo ha sido responder a la cuestión: ¿cuál es la mejor y posible aproximación del derecho a esta cuestión? Valorando los pros y contras de diversas opciones identificadas en la doctrina, desde una aproximación ius privatista como la que lleva elaborando la Conferencia Internacional de Derecho Internacional Privado de La Haya, ${ }^{1}$ pasando por soluciones indirectas aprovechando la Organización Mundial del Comercio o la Organización Internacional del Trabajo, he buscado justificar la conveniencia de un mecanismo convencional de protección de derechos humanos ad hoc para la gestación por sustitución.

La aproximación a una eventual regulación internacional de la gestación por sustitución desde la protección de los derechos humanos no es una novedad, pues desde este discurso se ha venido defendiendo la protección del derecho al estándar más alto posible de salud (incluyendo la salud reproductiva) de los padres de intención gracias a los avances científicos, junto al derecho de la mujer a prestar un servicio remunerado sin sufrir explotación. Esa aproximación existente hasta la fecha me parece incompleta porque no toma en consideración la protección de los derechos del niño objeto del contrato de gestación por sustitución.

En esta tesitura, mi segundo objetivo ha sido hacer más visible la presencia del niño y de sus derechos en un eventual régimen convencional de protección de derechos humanos ad hoc para la gestación por sustitución. A tal fin me he valido de los avances científicos publicados en los últimos años sobre epigenética y sobre los riesgos epigenéticos que para la salud

1 Disponible en: https://www.hcch.net/en/projects/legislative-projects/parentage-surrogacy (fecha de consulta: 20 de agosto de 2015). 
Esta revista forma parte del acervo de la Biblioteca Jurídica Virtual del Instituto de Investigaciones Jurídicas de la UNAM

humana pueden derivarse trasladando esos resultados al ámbito concreto de los contratos internacionales de gestación por sustitución. En particular, he usado datos biomédicos que, con las debidas cautelas, se dan por ciertos en la comunidad científica especializada, tales como el carácter transmisible de las epimutaciones (de madres biológicas a hijos), o el carácter variable de las epimutaciones según la etapa de desarrollo de cada individuo. Asimismo, la importancia de la dieta de la madre biológica y del estrés de ésta en la generación de tales epimutaciones en su feto o hijo recién nacido. Con ello he pretendido demostrar que la gestación por sustitución no es una práctica acordada entre adultos que no perjudica a terceros y que necesariamente produce beneficios para todos los sujetos implicados.

Finalmente, como tercer objetivo de este trabajo, he querido proponer un marco inspirador para el legislador internacional a la hora de elaborar un eventual convenio de protección de derechos humanos ad hoc para la gestación por sustitución. Con tal fin he defendido la idoneidad de la teoría del justo equilibrio de los distintos intereses en juego, como la viene desarrollando desde hace décadas el Tribunal Europeo de Derechos Humanos y ha aplicado recientemente en sus sentencias del 26 de junio de 2014 (Casos Labasse y Menesson con Francia) y del 27 de enero de 2015 (Caso Paradiso y Campanelli contra Italia), las únicas hasta la fecha decididas en relación con la gestación por sustitución y el interés superior del menor. Aun cuando las cuestiones epigenéticas no se plantean en dicha jurisprudencia, me parece relevante invocarla en el sentido de que si el interés superior del menor debe ser considerado en relación con su derecho a la identidad como parte de su vida privada, como hasta ahora, tanto más debería serlo en atención a la efectiva protección de su derecho a la salud.

Siguiendo a autores como Reed y Padkocimate, esta investigación sociojurídica se ha hecho desde una aproximación del derecho internacional y europeo siguiendo una metodología científica denominada desk table research, en la que se combinan diversas técnicas metodológicas: examen de la doctrina relevante, para recoger información genérica, identificar problemas clave, sus posibles soluciones, así como las posibles lagunas existentes a nivel de investigación, análisis crítico-jurídico de la normativa existente junto con el estudio de casos concretos, revelando lagunas y deficiencias y avanzando de lege ferenda propuestas válidas para los nuevos retos. ${ }^{2}$

2 Reed, K., y Padkocimate, A., The Right Toolkit. Applying Research Methods in the Science of Human Rights, Berckley, University of California, 2012, p. 2. 
Esta revista forma parte del acervo de la Biblioteca Jurídica Virtual del Instituto de Investigaciones Jurídicas de la UNAM

Los objetivos perseguidos y la metodología aplicada en este trabajo justifican la sistemática seguida en su desarrollo así como las conclusiones alcanzadas al final del mismo, con independencia de que sean o no compartidas, pues sólo son opiniones en derecho y no verdades absolutas. Así, me parecía lógico hacer una presentación del estado de la cuestión, partiendo del debate ético-económico en torno a la gestación por sustitución: un negocio a escala global con defensores y detractores por consideraciones morales y de orden público, que no cuenta con una regulación internacional al respecto, y que un examen de derecho comparado arroja un escenario muy complejo.

La situación de no regulación siguiendo el clásico postulado liberal del laissez faire, laissez passer partía de la premisa antes apuntada de que los contratos de gestación por sustitución eran mayoritariamente considerados como una práctica acordada entre adultos que no perjudicaba a terceros y que necesariamente producía beneficios para todos los sujetos implicados. Como estos sujetos (las partes contractuales) eran los padres de intención y la madre biológica gestante, esa afirmación se sostendría en principio. Sin embargo, desde hace años se viene investigando sobre la influencia del medio ambiente y de las condiciones de vida sobre el genoma (la epigenética) y decidí analizar la eventual incidencia de la epigenética en la gestación por sustitución, siendo, salvo error por mi parte, el primero en hacerlo.

Tomando en consideración el carácter transmisible de las epimutaciones (de madres a hijos) y el carácter variable de las mismas según la etapa de desarrollo de cada individuo, destaco en este artículo la posible influencia de dos factores (la dieta de la madre biológica y el riesgo de estrés durante la última fase de su embarazo) en la formación de epimutaciones que - con las debidas cautelas y a la luz del estado actual de la ciencia- conllevan un riesgo para la salud futura del niño gestado por sustitución. Ese análisis que desarrollo en el epígrafe tercero de este artículo, me permitirá, en el epígrafe siguiente, reforzar la idea de la necesidad de una regulación internacional de la gestación por sustitución a partir de un instrumento convencional de protección de derechos humanos ad hoc que proteja los derechos de los padres de intención y de la madre gestante junto con los derechos de los niños así concebidos.

A modo de inspiración para el legislador internacional de un instrumento convencional de protección de los derechos humanos ad hoc para la gestación por sustitución que tome en consideración todos los intereses en juego, en el epígrafe quinto de este trabajo presento sucintamente la expe- 
riencia del Tribunal Europeo de Derechos Humanos aplicando la teoría del justo equilibrio de los intereses en juego en los Casos Labassee y Mennesson contra Francia en 2014, y en el Caso Paradiso y Campanelli contra Italia en 2015. Son los únicos casos que hasta la fecha ha decidido este tribunal internacional en relación con la gestación por sustitución y el interés superior del menor. Aun cuando las cuestiones epigenéticas no se plantearon en los mismos, dicha jurisprudencia me parecía relevante invocarla como fuente de inspiración para un eventual convenio internacional en la medida en que en el mismo habría de ser tenido en consideración el interés superior del menor, no sólo como hasta ahora, en relación con su derecho a la identidad como parte de su vida privada, sino, además, en atención a la efectiva protección de su derecho a la salud.

Finalizo presentando en el epígrafe sexto las conclusiones alcanzadas, si bien con carácter provisional, y la bibliografía principal manejada en la realización de este estudio.

\section{EL DEBATE ÉTICO-ECONÓMICO EN LA GESTACIÓN POR SUSTITUCIÓN COMO CONDICIONANTE PREVIO PARA UN DEBATE JURÍDICO SOBRE LA CUESTIÓN}

Al igual que se aprecia en relación con otras cuestiones suscitadas por los avances y prácticas científicas en el campo de la biomedicina y sus implicaciones para el ser humano, ${ }^{3}$ la gestación por sustitución se caracteriza por una regulación internacional inexistente y las aproximaciones nacionales que se evidencian desde una perspectiva de derecho comparado - particularmente evidente a nivel europeo- pueden ser calificadas de "normatividad de geometría variable". Geometría, en primer lugar, por cuanto las posibles aproximaciones normativas a esta cuestión son, respectivamente, la permisión, la restricción, la prohibición y la no regulación. ${ }^{4}$ Variable,

3 Como es el caso, por ejemplo, de la investigación embrionaria humana. Puede verse, al respecto, Spar, D., y Harrington, A., "Selling Stem Cell Science: How Markets Drive Law along the Technological Frontier, American Journal of Law and Medicine, vol. 33, núm. 4, 2007, pp. 541-565; García San José, D. (coord.), European Normative Framework for Biomedical Research in Human Embryos, Cizur menor, Thomson-Reuter Aranzadi, 2013.

4 Cfr. a nivel internacional The Parentage/Surrogacy Project: An Updating Note, Preliminary 
Esta revista forma parte del acervo de la Biblioteca Jurídica Virtual del Instituto de Investigaciones Jurídicas de la UNAM

además, por cuanto las combinaciones de las aproximaciones normativas a nivel nacional se multiplican en función de que se distinga en nuestra comparativa la posición de los Estados en relación con la gestación por sustitución o respecto de las consecuencias jurídicas para las partes implicadas en este tipo de prácticas. ${ }^{5}$

Esta situación lamentable — desde el principio de seguridad jurídica_— ${ }^{6}$ no debe sorprender del todo, ya que es coherente con la démarche histórica del derecho frente a los avances científicos y tecnológicos. ${ }^{7}$ Más inquietante, por el contrario, resulta comprobar cómo la práctica de la gestación por sustitución, habiendo devenido en un negocio global, ${ }^{8}$ que mueve billones

Document núm. 3, febrero de 2015, preparado en el seno de la Conferencia Internacional de Derecho Internacional Privado de La Haya (disponible en: www.hcch.net). Para una aproximación a la situación en Europa, véase: El régimen de la sustitución en los Estados miembros de la Unión Europea, Doc. PE 474. 403 del Parlamento Europeo, en particular, el cuadro resumen de los distintos enfoques jurídicos adoptados por los Estados miembros de la Unión, pp. 11-13.

5 Es el caso, por ejemplo, de un Estado que prohíbe la gestación por sustitución en su territorio al tiempo que permite regularizar a sus nacionales las relaciones parentales-filiales derivadas de una gestación por sustitución realizada en el extranjero.

6 La práctica de la gestación por subrogación es una realidad a la que el derecho — como herramienta reguladora de las acciones sociales - debe dar una respuesta. Rodríguez-Yong, A., y Martínez-Muñoz, K., "El contrato de maternidad subrogada: la experiencia estadounidense”, Revista de Derecho (Valdivia), vol. XXV, núm. 2, 2012, p. 80.

7 Véase García San José, D., "Claves para un régimen internacional de la clonación humana”, Anuario Mexicano de Derecho Internacional, 2005, pp. 153-171. Como allí señalo, las cuatro posibles opciones que la historia muestra son: el incentivo de la actividad mediante la financiación gubernamental y la protección de patentes; la abstención reguladora, consecuente con el laissez faire de la Revolución industrial del siglo XIX; la opción de la regulación restrictiva, controlando o desincentivando una actividad o parte de la misma, como sucedió a raíz de la Gran Depresión de 1929 que siguió a la expansión económica del siglo XIX; finalmente, la opción más frecuentemente repetida en el pasado: la prohibición de la idea o descubrimiento en cuestión.

8 Véase, en este sentido, Brunet, L., "La globalization internationale de la gestation pour autrui”, Travail, Genre et Societés, núm. 2, 2012, pp. 199-205. Datos económicos y cifras contrastadas por países que confirman esta afirmación pueden obtenerse en el trabajo desarrollado por la Conferencia Internacional de Derecho Internacional Privado de La Haya, véase el documento The Parentage/Surrogacy Project: an Updating Note, preparado por el Permanent Bureau de la Conferencia Internacional de Derecho Internacional Privado de La Haya (HCCH), febrero de 2015, disponible en: https: / / assets.hcch.net/docs/82d31f31-294f-47fe-91 66-4d9315031737.pdf (fecha de consulta: 20 de agosto de 2015). 
Esta revista forma parte del acervo de la Biblioteca Jurídica Virtual del Instituto de Investigaciones Jurídicas de la UNAM

de dólares anualmente, ${ }^{9}$ al que los expertos no se atreven a poner límites, ${ }^{10}$ que plantea problemas jurídicos de hondo calado para los Estados desde hace al menos una década, no sólo desde el punto del Derecho Civil y de la filiación, ${ }^{11}$ sino especialmente desde consideraciones éticas y jurídicas, ${ }^{12}$ aunque no cuente con una regulación internacional, por falta de consenso entre los Estados de la comunidad internacional, a pesar de que con la misma se podría resolver gran parte de los problemas suscitados. ${ }^{13} \mathrm{Mi}$ inquietud — siempre desde el estricto punto de vista del jurista — se justifica por dos razones ya señaladas desde la doctrina: por una parte, está el hecho de que la práctica de la gestación por sustitución es una realidad y por tanto,

9 Como se recoge en un interesante estudio. Véase Nelson, E., "Global Trade and Assisted Reproductive Technologies: Regulatory Challenges in International Surrogacy”, Journal of Law, Medicine and Ethics, vol. 41, núm. 1, 2013, pp. 240-253.

10 La comunidad científica especializada en técnicas reproductivas coincide en señalar que han aumentado los problemas de infertilidad y de esterilidad en las últimas décadas y que esta tendencia se incrementará aún más en los próximos años. Sánchez Morales, H., "Impactos de la reprogenética en las tendencias demográficas y en las estructuras familiares”, Arbor, vol. 187, 2011 , p. 765.

11 Si algo resulta claro para los juristas civilistas en los tiempos que vivimos no es sólo que las técnicas de reproducción asistida demanden cambios en la normativa vigente relativa a la filiación, sino especialmente el hecho de que la nueva filiación que ha surgido de estas técnicas no puede ser abarcada y comprendida plenamente sólo desde esta disciplina del derecho. Lamm, E., "La importancia de la voluntad procreacional en la nueva categoría de la filiación derivada de las técnicas de reproducción asistida”, Revista de Bioética y Derecho, núm. 24, 2012, p. 79.

12 Drabiak, K. et al., "Ethics, Law and Commercial Surrogacy: a Call for Uniformity", The Journal of Law, Medicine \& Ethics, vol. 35, núm. 2, 2007, pp. 300-309; Deonandan, R. et al., "Ethical Concern for Maternal Surrogacy and Reproductive Tourism", Journal of Medical Ethics, vol. 38, núm. 12, 2012, p. 742; Ettinger, D., "Genes, Gestation and Social Norms", Law and Philosophy: an International Journal for Jurisprudence and Legal Philosophy, vol. 31, núm. 2, 2012, pp. 243-268.

13 Como señala Noelia Igareda, la hipotética regulación de la gestación por sustitución daría respuesta a una creciente demanda social, supondría un obstáculo al turismo reproductivo, constituiría un instrumento para garantizar el derecho a la reproducción de cierta parte de la población, ofrecería seguridad jurídica a las partes y permitiría un control legal de las condiciones para no incurrir en situaciones de explotación o de falta de ética. Igareda González, N., "La inmutabilidad del principio «mater semper certa est»y los debates actuales sobre la gestación por sustitución en España”, Universitas. Revista de Filosofía, Derecho y Política, núm. 21, 2015, p. 19. Aun cuando esta autora se refiere a una regulación en España que sustituya la prohibición incluida en el artículo 10 de la Ley 14/2006 sobre Técnicas de Reproducción Humana Asistida, coincidiendo con su predecesora Ley 35/1988, pensamos que son plenamente extrapolables a un contexto internacional. 
Esta revista forma parte del acervo de la Biblioteca Jurídica Virtual del Instituto de Investigaciones Jurídicas de la UNAM

el derecho, como herramienta reguladora de las acciones sociales, debe asumir una postura determinada frente a ésta $;{ }^{14}$ por otra parte, está la evidencia de los últimos años, de que los problemas jurídicos de la gestación por sustitución no se resuelven dejando las cosas como están. ${ }^{15}$

A mero título de ejemplo, aun cuando mucho se ha hablado en la prensa en los últimos tiempos respecto de esta cuestión, se omitía cualquier referencia al hecho de que estos vientres de alquiler que son legales en países como Estados Unidos, India, Ucrania o Rusia, también pueden venir acompañados de un catálogo de cualidades y características que los futuros padres — clientes de estas empresas de procreación artificial— pueden elegir para su "bebé a la carta": color de ojos, de piel, determinada carga genética añadida o eliminada, etcétera. ${ }^{16}$ Sin duda, estas intervenciones sobre el bebé pueden atentar contra su dignidad pues, como reconoció recientemente el abogado general de la Unión Europea en sus conclusiones presentadas en el Asunto C-34/10 el 11 de marzo de 2011:

Procede recordar aquí, por otra parte, que la Directiva 98/44, en nombre del principio de la dignidad y de la integridad de las personas, prohíbe la patentabilidad del cuerpo humano en los diferentes estadios de su constitución y de su desarrollo, incluidas las células germinales. De este modo, demuestra que la dignidad humana es un principio que debe aplicarse no sólo a la persona humana existente, al niño nacido, sino también al cuerpo humano desde el primer estadio de su desarrollo, es decir, el de la fecundación [énfasis añadido].

Partiendo de la premisa señalada — la necesidad de encontrar una respuesta en derecho a los problemas jurídicos que la gestación por sustitución plantea puesto que estos problemas, que se han incrementado en los últimos años, no se van a resolver por sí solos_-, la consiguiente pregunta es: ¿cuál es la mejor y posible aproximación del derecho a esta cuestión? ${ }^{17}$

14 Rodríguez-Yong, C. y Martínez Muñoz, K., "El contrato de maternidad subrogada: la experiencia estadounidense”, Revista de Derecho (Valdivia), vol. XXV, núm. 2, 2010, p. 80.

15 Davis, E., "The Rise of Gestational Surrogacy and the Pressing Need for International Regulation”, Minnesota Journal of International Law, vol. 21, núm. 1, 2012, p. 144.

16 Aunque la razón parece rechazar como posible tales prácticas próximas a la eugenesia, el autor de esta investigación cuenta con el testimonio directo de padres de intención que confirman la veracidad de las mismas por su propia experiencia en California (USA).

17 En nuestro análisis descartamos la prohibición y la abstención reguladora por los riesgos 
Esta revista forma parte del acervo de la Biblioteca Jurídica Virtual del Instituto de Investigaciones Jurídicas de la UNAM

En este punto, la complejidad que rodea a la gestación por sustitución comienza a manifestarse con mayor claridad, motivada en gran medida por dos factores: de una parte, la tensión dialéctica entre los condicionantes éticos y económicos en juego; de otra parte, la presencia distorsionadora de distintos sujetos y actores internacionales: Estados, organizaciones internacionales, empresas con ánimo de lucro, personas particulares con muy desigual estatus social y económico que participan en los contratos de gestación por sustitución, organizaciones no gubernamentales, etcétera. En este complejo contexto, es necesario aportar un centro de gravedad que imprima un orden sistémico a todas las consideraciones posibles en esta materia, priorizando y relativizando éstas. ${ }^{18}$

De entrada, la regulación debe ser internacional, pues si se quiere efectiva no hay lugar a dejar margen para santuarios territoriales en los que puedan llevarse a cabo prácticas aberrantes que desplieguen efectos jurídicos en el resto de Estados. Debe tener, además, una base ética en su fundamentación — si se quiere que esa regulación sea efectivamente cumplida incluso por aquellos Estados cuyas sociedades han mostrado su rechazo a la gestación por sustitución - sin que esa consideración ética sea excluyente de la inclusión de otras consideraciones en la necesaria regulación de la gestación por sustitución, en particular, las relaciones de filiación y su reconocimiento por el derecho a partir de las nuevas técnicas de reproducción asistida. ${ }^{19}$ Así, desde el punto de vista del derecho internacional privado, son tres las grandes cuestiones involucradas: el problema de la jurisdicción competente, la determinación del derecho aplicable a la relación jurídica y el reconocimiento y ejecución de sentencias en litigios amistosos en las que un juez da por válida una filiación derivada de un contrato privado de gestación por sustitución. ${ }^{20}$ Esta última es, para esta disciplina jurídica, la

de la proliferación de un mercado negro de la gestación por sustitución o de un mercado tan liberalizado en el que al no existir regulación alguna, la cosificación de las personas que participan en estos contratos — mujer gestante e hijo gestado — pueda dar lugar a aberrantes actos con seres humanos.

18 Ekberg, M., "Ethical, Legal and Social Issues to Consider when Designing a Surrogacy Law”, Journal of Law and Medicine, vol. 21, núm. 3, 2014, pp. 728-738; Fenton-Glynn, C., "Outsourcing Ethical Dilemmas: Regulating International Surrogacy Arrangements", Medical Law Review, vol. 24, núm. 1, 2016, pp. 59-75.

19 Lamm, E., "La importancia de la voluntad procreacional en la nueva categoría de la filiación derivada de las técnicas de reproducción asistida”, op. cit., pp. 78 y 79

20 Scotti, L., "La maternidad subrogada en la legislación y jurisprudencia argentina", Re- 
Esta revista forma parte del acervo de la Biblioteca Jurídica Virtual del Instituto de Investigaciones Jurídicas de la UNAM

verdadera cuestión en juego: ¿está un Estado obligado a reconocer la filiación legal establecida en el extranjero de un niño nacido mediante un contrato de gestación por sustitución con sus padres de intención con los que no tiene un vínculo genético? ${ }^{21}$

Siendo relevante y necesaria una aproximación jurídica a estas cuestiones, ${ }^{22}$ en mi opinión, no es la más urgente ni la principal si nos ubicamos en un discurso centrado en la protección internacional de los derechos humanos. Antes al contrario, defiendo desde estas páginas que el principio del respeto de la dignidad humana y la obligación internacional de proteger los derechos humanos de las partes más vulnerables en los contratos privados de gestación por sustitución - la mujer gestante y el niño que engendrase convierten en referentes esenciales en la regulación internacional de la gestación por sustitución.

Desde el punto de vista de los derechos humanos, la necesidad de una regulación internacional pretende dar solución a cuestiones diversas. Por una parte, se invoca el derecho humano a la salud reproductiva, ${ }^{23}$ incluyendo la capacidad de procrear sin riesgos gracias a los avances en las técnicas de reproducción asistida. ${ }^{24}$ De este modo, la gestación por sustitución es vista como una técnica más que la ciencia dispone para hacer efectivo este derecho humano. ${ }^{25}$ Desde esta perspectiva se entiende la medida aprobada en

vista digital En Letra, 2014, p. 55, disponible en: www.oaji.net (fecha de consulta: 20 de agosto de 2015).

21 Beaumont, P. y Trimmings, K., "Recent Jurisprudence of the European Court of Human Rights in the Area of Cross-border Surrogacy: Is there Still a Need for Global Regulation of Surrogacy?", Bagioni, G. et al., Migrant Children in the XXI Century. Selected Issues of Public and Private International Law, Editoriale Scientifica, 2016 (en prensa).

22 Véase, en este sentido, el excelente trabajo publicado en 2016: González Martín, N. y Albornoz, Ma. M., “Aspectos transfronterizos de la gestación por sustitución”, Anuario Mexicano de Derecho Internacional, vol. XVI, 2016, disponible en: http: / /www2.juridicas.unam. $m_{x} / 2016 / 01 / 28 /$ aspectos-transfronterizos-de-la-gestación-por-sustitucion (fecha de consulta: 20 de agosto de 2015).

23 Casado Blanco, M. e Ibáñez Bernáldez, M., "Reflexiones legales y éticas en torno a la maternidad subrogada”, Revista Española de Medicina Legal, vol. 40, núm. 2, 2014, pp. 59 y 60.

24 "Everyone's right to the highest attainable standard of physical and mental health, including reproductive and sexual health, without discrimination of any kind is the core right to health and must be read, in addition, relating other human rights”. Committee on Economic, Social and Cultural Rights (CESCR) General Comment No. 14 (11/8/2000) on the Right to the Highest Attainable Standard of Health, parágrafo 4.

25 El derecho a la salud reproductiva debe ser considerado también a la luz del derecho a 
Esta revista forma parte del acervo de la Biblioteca Jurídica Virtual del Instituto de Investigaciones Jurídicas de la UNAM

Reino Unido desde comienzos de 2015 en el sentido de permitir la creación de embriones de tres padres: el óvulo de una madre al que se ha sustituido una parte de su carga genética defectuosa por el de otra mujer sana y que es fecundado por el esperma del padre. Con el fin de prevenir determinadas enfermedades hereditarias, se reemplaza parte del ADN mitocondríaco que comprende 37 de alrededor de los 20,000 genes que nos conforman y está relacionado con graves enfermedades que afectan a los niños, empeorando sus condiciones de vida conforme crecen. ${ }^{26}$ De igual modo, se entiende la posibilidad legalmente permitida en países como Estados Unidos y Canadá de la reproducción artificial intrafamiliar con toda la problemática jurídica que puede plantear. ${ }^{27}$

Desde el punto de vista de los derechos humanos, la necesidad de una regulación internacional responde al deseo de evitar la explotación de mujeres pobres o económicamente vulnerables que se prestan a alquilar sus vientres e, incluso, a donar sus propios óvulos, ${ }^{28}$ por ejemplo, exigiendo

procrear, reconocido en el artículo 16 de la Declaración Universal de los Derechos Humanos. Si el derecho a la salud se concreta en el derecho a disfrutar del nivel más alto posible de salud y, si este derecho incluye la dimensión de salud reproductiva, parecería injusto y desproporcionado privar a aquellos que sufren enfermedades de infertilidad, restringiendo sus posibilidades de ser padres sólo a la adopción, cuando la Ciencia hoy les permite ver cumplido su deseo de ser padres por otras vías.

26 Las malformaciones de ADN mitocondrial afectan a uno de cada 200 niños y sólo uno de cada 6500 desarrolla los casos más graves de alteraciones de ADN mitocondrial para los que no se conocen cura alguna. Sample, I., "Three-Parents' Babies Explained: What are the Concerns and are they Justified?”, 2 de febrero de 2015, disponible en: http://www.theguardian.com/ science/ 2015/feb/02/three-parent-babies-explained/ (fecha de consulta: 20 de agosto de 2015). Como se destaca en este artículo, las principales objeciones a esta aprobación normativa es que los cambios genéticos introducidos en el ADN mitocondrial van a afectar a los descendientes (futuras generaciones que no han prestado su consentimiento). A ello se suma, desde postulados religiosos, el hecho de que esta técnica exige la destrucción del óvulo originario de la madre con el ADN que se va a modificar (destrucción de una vida humana y ruptura del vínculo "padres"-hijo.

27 Se trata, por ejemplo, de una madre de edad avanzada que ante la imposibilidad de que su hija pueda hacerlo, dé a luz a su nieto, o una mujer que es al mismo tiempo madre y tía de su hijo en el caso de donación de ovocitos entre hermanos. López Guzmán, J. y Aparisi Miralles, Á., "Aproximación a la problemática ética y jurídica de la maternidad subrogada”, Cuadernos de Bioética, XXIII, 2012, p. 263.

28 El sentimiento de explotación "neocolonial" es tan evidente en países que son destino preferente de este turismo reproductivo por sus bajos costes — como es el caso de la Indiaque se ha suscitado un profundo debate académico sobre la necesidad de restringir e, incluso, 
Esta revista forma parte del acervo de la Biblioteca Jurídica Virtual del Instituto de Investigaciones Jurídicas de la UNAM

garantías de que su participación en este tipo de contratos se realiza sobre la base de un consentimiento libre e informado cuando se trata de un contrato oneroso. La propuesta de que la gestación por sustitución sea altruista y no lucrativa - que a veces se defiende como vía de evitar la explotación de esas mujeres gestantes - es fuertemente criticada desde voces feministas que encuentran un paralelismo entre permitir la gestación por sustitución altruista — sin compensación económica — con la tradicional consideración del desempeño de las tareas domésticas como "actos de amor maternal" sin carácter económico aunque se trate de un trabajo y de una contribución económica real a la vida familiar. ${ }^{29}$

También se ha propuesto, a fin de evitar la explotación de mujeres pobres o económicamente vulnerables, que sólo se permita participar en este tipo de contratos a aquellas que cuentan con suficientes recursos financieros. ${ }^{30}$ Se parte de la premisa de que la gestación por sustitución es un contrato laboral como otros muchos desde la teoría del dualismo, ${ }^{31}$ en el que la mujer — en el ejercicio de su autonomía — ${ }^{32}$ realiza libremente ${ }^{33}$ un servicio

prohibir este lucrativo negocio. Véase Saravanan, Sh., "Global Justice, Capabilities Approach and Commercial Surrogacy in India”, Medicine, Health care and Philosophy, vol. 18, núm. 3, 2015, pp. 295-307, Howard, S., "Proposed Ban on Foreigners Using India Surrogacy Services Sparks Protests”, British medical Journal, núm. 351, 2 de noviembre de 2015. Se insiste en destacar, además, los efectos "colaterales" de este tipo de turismo reproductivo en los sistemas de salud de los países en desarrollo: privilegiando el acceso de extranjeros a recursos médicos escasos cuando los propios ciudadanos de esos países sufren de manera desproporcionada altos niveles de mortalidad infantil y maternal. Donchin, A., "Reproductive Tourism and the Quest for Global Gender Justice”, Bioethics, vol. 24, núm. 7, 2010, p. 328.

29 Shanley, M. L., "Making Babies, Making Families. What Matters most in an Age of Reproductive Technologies, Surrogacy, Adoption and Same-Sex and Unsued Parents", Beacon Press, Boston, 2011, p. 107.

30 Ibidem, p. 109.

31 Según la cual la persona es un ser pensante y su cuerpo es una cosa de la que puede disponer libremente. López Guzmán, J. y Aparisi Miralles, Á., “Aproximación a la problemática ética y jurídica de la maternidad subrogada”, cit., p. 259.

32 Ainsworth, S., "Bearing Children, Bearing Risks: Feminist Leadership for Progressive Regulation of Compensated Surrogacy in the United States”, Washington Law Review, vol. 89, núm. 4, 2014, pp. 1077-1123.

33 Se ha propuesto desde la doctrina, por ejemplo, la conveniencia de que las gestantes por subrogación realicen cursos formativos a partir de la experiencia de otras gestantes, en los que se les forme sobre sus derechos y obligaciones como gestantes a fin de que su consentimiento sea realmente libre e informado. Véase Damelio, J. y Sorensen, K., "Enhancing Autonomy in Paid Surrogacy”, Bioethics, vol. 22, núm. 5, 2008, p. 269. 
Esta revista forma parte del acervo de la Biblioteca Jurídica Virtual del Instituto de Investigaciones Jurídicas de la UNAM

(gestar al bebé por otra mujer) por el que debe recibir una contraprestación justa a fin de evitar su explotación. ${ }^{34}$ Se asume aquí "explotación de la mujer", en un sentido restrictivo, como usar algo de modo injusto, esto es, sin compensar adecuadamente por ello; si bien en el debate sobre la gestación por sustitución se sostiene igualmente "explotación", en un sentido amplio, por utilizar a una mujer como un instrumento (deshumanización o cosificación de las madres gestantes) con independencia de la compensación económica que reciba.

Esta aproximación ha recibido múltiples críticas y puede parecer insuficiente dado que cada vez más voces reclaman prestar mayor atención a los derechos de los niños - la más sensible de las dos más vulnerables partes en un contrato de gestación por sustitución - en la medida en que al no existir éstos en el momento de la celebración del contrato, no se puede exigir su consentimiento $^{35}$ (se presume su voluntad de querer nacer mediante esta técnica), con lo que su estatus se asemeja más al de "producto" resultante del mismo, con grave riesgo para su dignidad al tratar como mercancía la vida humana. Este riesgo se ha demostrado real en aquellos casos en los que el bebé nacido mediante estas técnicas ha sido rechazado como "defectuoso" por los padres de intención. ${ }^{36}$ Con ello, se pone de manifiesto, como señalan algunos autores, que la gestación por sustitución no es, como algunos pretenden, una práctica acordada entre adultos que no perjudica a terceros y que necesariamente produce beneficios para todos los sujetos implicados. ${ }^{37}$

34 Wilkinson, S., "The Exploitation Argument against Commercial Surrogacy”, Bioethics, vol. 17, núm. 2, 2003, p. 171.

35 Hanna, J., "Revisiting Child-based Objections to Commercial Surrogacy", Bioethics, vol. 24, núm. 7, 2010, p. 341.

36 Como el Caso de la niña Manji (nacida en 2008 en la India mediante un contrato entre una mujer hindú y una pareja japonesa que se divorció dándose la situación que ninguna de las partes quería hacerse cargo de la niña); el caso Stwer-Malahoff (el padre de intención rechazó el niño nacido en 1982 por nacer con retraso mental); más reciente, en 2013, el Caso Crystal Kelley, en el que la madre gestante recibió la oferta de una considerable suma de dinero por los padres de intención para que interrumpiera su embarazo al determinarse que el bebé que gestaba sufría graves taras. Overall, Ch., "Reproductive Surrogacy and Parental Licensing", Bioethics, vol. 29, núm. 5, 2015, p. 354.

37 López Guzmán, J. y Aparisi Miralles, Á., "Aproximación a la problemática ética y jurídica de la maternidad subrogada”, cit., p. 261. 
Ahora bien, salvo error por mi parte, hasta la fecha no se ha considerado la epigenética al hablar del interés superior del menor en el contexto de la gestación por sustitución. ${ }^{38}$ En este contexto, el análisis que desarrollo en el epígrafe siguiente centrado en el examen de los riesgos epigenéticos derivados de la gestación por sustitución para la salud del niño así concebido, me servirá para hacer más visible la presencia del niño y de sus derechos en un eventual régimen convencional de protección de derechos humanos ad hoc para la gestación por sustitución. A tal fin utilizaré los resultados de los avances científicos publicados en los últimos años sobre epigenética y sobre los riesgos epigenéticos que para la salud humana pueden derivarse, trasladando esos resultados al ámbito concreto de los contratos internacionales de gestación por sustitución. En particular, usaré datos biomédicos que, con las debidas cautelas, se dan por ciertos en la comunidad científica especializada, tales como el carácter transmisible de las epimutaciones (de madres biológicas a hijos), o el carácter variable de las epimutaciones según la etapa de desarrollo de cada individuo. Me referiré, asimismo, a la importancia de la dieta de la madre biológica y del estrés de ésta en la generación de tales epimutaciones en su feto o hijo recién nacido. Con ello trataré de demostrar que la gestación por sustitución no es una práctica acordada entre adultos que no perjudica a terceros y que necesariamente produce beneficios para todos los sujetos implicados.

\section{EVENTUAL INCIDENCIA DE LA EPIGENÉTICA}

EN LA GESTACIÓN POR SUSTITUCIÓN

Cada vez más estudios demuestran la conexión entre las condiciones ambientales, nutricionales, socio-económicas y psicológicas en el desarrollo físico y médico, presente y futuro, de una persona y en el de sus descendientes. La epigenética es una vieja conocida de la comunidad científica. De

38 Véase, entre algunos de los trabajos más representativos, Agnafors, M., "The Harm Argument Against Surrogacy Revisited: Two Versions not to Forget”, Medicine, Health Care and Philosophy, vol. 17, núm. 3, 2014, pp. 357-363; Mcmillan, J., "Making sense of Child Welfare When Regulating Human Reproductive Technologies", Journal of Bioethics Inquiry, vol. 11, núm. 1, 2014, pp. 47-55, Sifris, A., "The Family Courts and Parentage of Children Conceived Through Overseas Commercial Surrogacy Arrangements: a Child-Centred Approach”, Journal of Law and Medicine, vol. 23, núm. 2, 2015, pp. 396-412. 
Esta revista forma parte del acervo de la Biblioteca Jurídica Virtual del Instituto de Investigaciones Jurídicas de la UNAM

hecho, la primera vez que se utilizó este término fue en 1942, por Conrad Waddington, en un sentido próximo al que tiene en la actualidad, describiendo las interacciones entre los genes y su entorno. ${ }^{39}$

Hoy en día, la epigenética puede entenderse como "el estudio y análisis de los cambios de las funciones de los genes que son heredables y que no involucran cambios en la secuencia original del ADN, lo que significa determinar las expresiones alternas de un mismo gen”. ${ }^{40}$ Así, la epigenética indica cambios heredables en la estructura y organización del ADN que aun cuando no suponen una alteración de la secuencia de los nucleótidos, modifican la expresión génica y conllevan cambios heredables en el fenotipo. ${ }^{41}$ Dicho de otro modo, las condiciones de vida que experimente una persona (por ejemplo, si vivió en un ambiente con mayor o menor salubridad o si desarrolló unos hábitos vitales más o menos saludables) de algún modo se quedan archivadas en un "disco duro de memoria" que — de un modo poco conocido aún por los científicos — puede activarse décadas más tarde en esa persona e incluso en sus descendientes. Tales condiciones de vida determinan años más tarde una respuesta somática (por ejemplo, el desarrollo de enfermedades directamente conectadas a las mismas) en esas personas y en sus descendientes aun cuando estos últimos no las hayan experimentado directamente por sí mismos.

De eso trata la epigenética, de alteraciones en la modificación química del ADN que no implican cambios en su secuencia (el código genético en sí mismo), sino en el modo de expresión de dicho código a través de unas marcas. Gráficamente puede entenderse, siguiendo a Rothstein, con el siguiente símil: el código genético de una persona sería el hardware de un ordenador, mientras que la información epigenética sería el software que controla el hardware de dicho dispositivo. ${ }^{42}$ Se sabe que el epigenoma (el software de cada individuo o las marcas en su código genético) es muy sensible y receptivo a las influencias ambientales: dónde se vive, qué se come, cómo se vive (con mayor o menor estrés), qué tipo de trabajo se desarrolla,

39 Waddington, C., “The Epigenotype”, Endeavour, núm. 1, 1942, p. 18.

40 García Cavazos, R., "Epigenética: una explicación de las enfermedades hereditarias", Perinatol Reprod. Hum, 17, 2003, p. 58.

41 García Robles, R. et al., "Epignética: definición, bases moleculares e implicaciones en la salud y en la evolución humana", Revista Ciencias de la Salud, vol. 10, núm. 1, 2012, p. 61.

42 Rothstein, M. et al., "The Ghost in Our Genes: Legal and Ethical Implications of Epigenetics", Health Matrix Cleve, 19(1), 2009, p. 1. 
qué hábitos se tienen, etcétera. Sin embargo, aún se desconoce cómo se produce esta ósmosis o permeabilidad. ${ }^{43}$

Dos de las características de los cambios epigenéticos o epimutaciones son de especial relevancia para el caso de la gestación por sustitución. Me estoy refiriendo al carácter transmisible de las epimutaciones (de padres a hijos) y el carácter variable de las epimutaciones según la etapa de desarrollo de cada individuo.

\section{El carácter transmisible de las epimutaciones (de madres a hijos)}

La importancia de este primer dato es evidente: en la gestación por sustitución no es sólo — ni siquiera lo predominante — la carga genética de los padres de intención tanto en el supuesto en que ambos hayan aportado sus gametos (gestación por sustitución parcial o gestational surrogacy), como si es sólo el esperma del padre de intención el introducido en la gestante para fertilizar su óvulo (gestación por sustitución plena o complete surrogacy), sino la carga epigenética de la mujer que gesta al bebé por sustitución y que biológicamente es la madre del nasciturus al darlo a luz, con independencia de que legalmente no lo sea en virtud de un contrato privado inter partes - oficializado por una sentencia judicial en un litigio amistoso, por el que renuncia a sus derechos como madre sobre el bebé que ha alumbrado en favor de los padres de intención-. Como evidencian recientes estudios, las epimutaciones son inducidas, entre otros estímulos, por los cuidados maternos o por el estrés de la madre durante la gestación o inmediatamente después del parto. ${ }^{44}$

\section{El carácter variable de las epimutaciones}

según la etapa de desarrollo de cada individuo

La relevancia del segundo dato que hemos destacado es aún mayor en conexión con lo que acabamos de señalar a propósito del carácter transmisible

43 Idem.

44 Véase Gallou-Kabani, C. et al., "Nutri-Epigenomics: Lifelong Remodeling of our Epigenomes by Nutritional and Metabolic Factors and Beyond”, Clinical Chemistry \& Laboratory, núm. 45, 2007, pp. 321-323. 
Esta revista forma parte del acervo de la Biblioteca Jurídica Virtual del Instituto de Investigaciones Jurídicas de la UNAM

de las epimutaciones. En este punto los autores coinciden en señalar que la edad a la que un organismo se expone a las epimutaciones es determinante para cuantificar el grado de incidencia de dicha epimutación, de manera que la etapa de gestación del feto y los meses posteriores al alumbramiento son los momentos de desarrollo del ser humano en los que éste resulta más proclive a experimentar dichas epimutaciones. ${ }^{45}$

Como han señalado Rothstein, Cai y Marchant, la epigenética proporciona un mecanismo para el ser humano en formación - en el útero o en los primeros estados de vida tras nacer- cuya misión es evaluar su entorno y ajustar su respuesta genética al mismo. En un continuo proceso de retroalimentación o feedback, el medio ambiente, la dieta, estilo de vida, estrés maternal, entre otros factores, permiten a un organismo en desarrollo ajustar su fenotipo (la expresión de sus genes) a su entorno anticipado, de manera que la epigenética actúa como un mediador entre el medio ambiente y el genoma. ${ }^{46}$

En su etapa embrionaria o de recién nacido, el cuerpo humano está programado para recopilar información de su entorno y a partir de esa información vuelve a ajustar su crecimiento. Esta adaptación de la expresión genómica sin alterar el propio código genético es lo que permite la epigenética. Volviendo al símil anterior, se cambia el software sin necesidad de tocar el hardware. ${ }^{47}$ Ahora bien, esa adaptación de la expresión genómica del ser humano en formación al entorno se ve alterada de manera dramática en el caso de la gestación por sustitución pues en la mayoría de los casos — de hecho, en casi todos los supuestos — se trata de un bebé "encargado" por padres de países desarrollados (europeos fundamentalmente) a mujeres gestantes en países en desarrollo (estando la India a la cabeza ${ }^{48}$ ) con unas

45 Véase, entre otros, Brennan, J. y Capel, B., "One Tissue, Two Fates: Molecular Genetic Events that Underlie Testis versus Ovary Development”, Nature Rev Genetics, núm. 5, 2004, p. 510; Dolinoy D., Weidman, J. y Jirtle, R., "Epigenetic Gene Regulation: Linking Early Developmental Environment to Adult Disease”, Reproductive Toxicology, núm. 23, 2007, p. 298.

46 Rothstein, M. et al., "The Ghost in Our Genes: Legal and Ethical Implications of Epigenetics", cit., p. 5.

47 Gorman, R., “The New Hereditary”, Protomag, 2007, p. 39, disponible en: http: / protomag.com/issues/2007_fall/pdfs/hereditary.pdf (fecha de consulta: 20 de agosto de 2016); Pray, L., "Epigenetics: Genome, Meet Your Environment", Scientist, 5 de julio de 2004, p. 14.

48 Pande, A., "Commercial Surrogacy in India: Manufacturing a Perfect Mother-Worker", Signs, vol. 35, núm. 4, 2010, pp. 969-992; Shetty, P., "India's Unregulated Surrogacy Industry”, The Lancet, vol. 380, núm. 9854, 10 de noviembre de 2012, pp. 1633-34; Dagar, T., et al., 
Esta revista forma parte del acervo de la Biblioteca Jurídica Virtual del Instituto de Investigaciones Jurídicas de la UNAM

condiciones ambientales, de dieta, de hábitos de vida, etcétera, muy diferentes respecto a las que se van a encontrar esos niños una vez que sean entregados a sus padres de intención y para las cuales no han sido predispuestos por las epimutaciones transmitidas por su madre biológica. Su entorno natural va a cambiar significativamente en un momento de su desarrollo celular en el que, como ya he destacado, más fácilmente pueden producirse epimutaciones que pueden dar lugar a enfermedades a desarrollar en su estado adulto — y que, además, transmitirá a sus descendientes-.

Se trata de enfermedades para las que su organismo en principio no estaría expuesto de haber seguido viviendo en el entorno ambiental, económico y social de su madre biológica. Así parece deducirse de los trabajos de autores como Andrew Feinberg, quien sostiene por un razonamiento lógico que si las epimutaciones pueden explicar un desarrollo normal de un ser humano en un entorno concreto, de igual manera, las interrupciones en las epimutaciones deben alterar necesariamente los programas normales de desarrollo de ese mismo ser humano (lo que se conoce como aberraciones epigenéticas) pudiendo comprometer negativamente su salud y bienestar. ${ }^{49}$

En efecto, cada vez está más aceptado entre la comunidad científica el hecho de que la predisposición a ciertas enfermedades manifestadas en la etapa adulta de una persona tienen su origen en epimutaciones originadas durante su etapa embrionaria. Siguiendo la teoría conocida como "early origins" (orígenes tempranos), según la cual la evolución de la plasticidad del desarrollo que permite que un organismo pueda adaptarse a las señales ambientales durante la vida temprana, también puede aumentar el riesgo de desarrollar enfermedades crónicas cuando hay un desajuste entre lo percibido en los primeros estados de desarrollo de la persona y lo que va a encontrar realmente en su etapa adulta. ${ }^{50}$ Se trata, entre otras, de enfermedades tardías comunes como la hipertensión, la diabetes tipo 2, la obesidad,

"Surrogacy in India: Current scenario", Indian Journal of Health and Wellbeing, vol. 6, núm. 5, 2015, pp. 534-535; Nadimpalli, S. y Venkatachalam, D., "Marketing Reproduction: Assisted Reproductive Technologies and Commercial Surrogacy in India”, Indian Journal of Gender Studies, vol. 23, núm. 1, 2016, pp. 87-104.

49 Feinberg, A., "Epigenetics at the Epicenter of Modern Medicine", 299 JAMA, 2008, p. 1348 .

50 Jirtle, R y Skinner, M., "Environmental Epigenomics and Disease Susceptibility", Nature Rev Genetics, vol. 8, 2007, p. 253. 
Esta revista forma parte del acervo de la Biblioteca Jurídica Virtual del Instituto de Investigaciones Jurídicas de la UNAM

la oclusión de las arterias coronarias, o enfermedades menos frecuentes como la esquizofrenia, el trastorno bipolar o el alzheimer. ${ }^{51}$

Los riesgos de sufrir epimutaciones que pueden comprometer la salud futura del niño nacido mediante la técnica de gestación por sustitución derivan de la propia utilización de las técnicas de reproducción asistida, frecuentemente utilizada cuando la madre gestante aporta su propio óvulo fecundado por esperma del padre de intención, o cuando se le implanta un óvulo a la madre de intención, fecundado in vitro con esperma del padre de intención o de un donante anónimo $;^{52}$ sin embargo, es sin duda la influencia materna la principal causa de epimutaciones en la gestación por sustitución a través de dos vías: la dieta y el estrés psicológico de la madre biológica (la mujer gestante).

\section{A. La dieta de la madre biológica}

Entre los múltiples estudios que se han realizado a este respecto, destaca uno que resulta pertinente mencionar en relación con la gestación por sustitución: se ha demostrado que la escasez nutricional en el desarrollo embrionario programa al ser humano en formación con un fenotipo epimutado gracias al cual maximizará la energía y los recursos durante el resto de su vida. Ahora bien, si las condiciones de esa persona cambian, por ejemplo, insertándose en una sociedad donde no va a tener escasez de comida sino todo lo contrario, entonces, la programación epigenética que experimentó en su etapa embrionaria estará en desajuste con su entorno y, por ello, muy

51 Mill, J. et al., "Epigenomic Profiling Reveals DNA-Methylation Changes Associated with Major Psychosis", Am J Hum Genetics, vol. 82, 2008, p. 697; Egger, G. et al., "Epigenetics in Human Disease and Prospects for Epigenetic Therapy”, Nature, núm. 429, 2004, pp. 457-460.

52 Las técnicas de fertilización in vitro y la inyección intracitoplasmática de espermatozoide han sido conectadas con al menos dos enfermedades: el síndrome de Beckwith-Wiedemann y el síndrome de Angelmans. Véase Maher, E. et al., "Epigenetic Risks Related to Assisted Reproductive Technologies: Epigenetics, Imprinting, ART and Icebergs?”, Human Reproduction, vol. 18, núm. 12, 2003, pp. 2508-2511, Sparago, A. et al., "Mechanisms Causing Imprinting Defects in Familial Beckwith-Wiedemann Syndrome with Wilms' Tumor", Human Molecular Genetics, vol. 16, 2007, pp. 254-255. Sin embargo, también han aparecido estudios en sentido contrario a dicha conexión epigenética, véase Santos, F. et al., "Evaluation of Epigenetic Marks in Human Embryos Derived from IVF and ICSI”, Human Reproduction, vol. 25, núm. 9, 2010, pp. 2387-2395. 
Esta revista forma parte del acervo de la Biblioteca Jurídica Virtual del Instituto de Investigaciones Jurídicas de la UNAM

probablemente desarrollará enfermedades como la obesidad o la diabetes tipo $2 .{ }^{53}$

En este mismo sentido, hay estudios que parecen confirmar la relación entre la dieta seguida por una madre durante su periodo de gestación - en particular si reduce la ingesta de alimentos que tienden a aumentar la metilación del ADN (como el ácido fólico, la metionina, la vitamina B12, la colina y la Betaína) y el padecimiento de algunas enfermedades en la edad adulta como la obesidad o la hipertensión arterial ${ }^{54} \mathrm{o}$, incluso, contribuir a la aparición de determinados tipos de cáncer-.${ }^{55}$ Más aún, el riesgo de padecimiento de estas enfermedades continuará en los descendientes de esa persona mientras no se logre revertir esa epimutación. ${ }^{56}$

\section{B. El estrés de la madre biológica}

En relación con el estado psicológico de la madre biológica, los estudios que se están desarrollando en los últimos años en este campo ${ }^{57}$ parecen confirmar, igualmente, que el mismo puede inducir cambios epigenéticos en sus descendientes y que dichos cambios afectarán a la salud futura de éstos. De modo especial, el estrés materno, tanto en el proceso de gestación como en los primeros meses de vida del bebé tras su alumbramiento, influirá en este sentido, y no es baladí recordar que con frecuencia la madre biológica padece un estado de estrés (dudas, arrepentimiento, miedo) en los meses últimos de su embarazo o inmediatamente tras dar a luz en los contratos privados de gestación por sustitución ${ }^{58}$ que afectará a la progra-

53 Stöger, R., "The Thrifty Epigenotype: An Acquired and Heritable Predisposition for Obesity and Diabetes?”, Bio Essays, núm. 30, 2008, pp. 156-160.

54 Waterland, R. et al., "Maternal Methyl Supplements Increase Offspring DNA Methylation at Axin Fused”, Genesis, núm. 44, 2006, pp. 401-403.

55 Ross, Sh., "Diet and DNA Methylation Interactions in Cancer Prevention", Ann NY Acad. Sci., núm. 983, 2003, pp. 197-204.

56 Cooney, G., “Germ Cells Carry the Epigenetic Benefits of Grandmother's Diet”, Proc. Nat'l Acad Sci, núm. 103, 2006, pp. 17071 y 17072.

57 A mero título ilustrativo, en 2007 se publicaron más de dos mil quinientos artículos científicos sobre epigenética. Véase Rothstein, M. et al., "The Ghost in Our Genes...”, cit., p. 9.

58 Los estudios que directa e indirectamente abordan los daños físicos y psicológicos que sufren las mujeres gestantes en países pobres son abundantes: Abrams, P., "The Bad Mother Stigma, Abortion and Surrogacy”, The Journal of Law, Medicine \& Ethics, vol. 43, núm. 2, 2015, 
Esta revista forma parte del acervo de la Biblioteca Jurídica Virtual del Instituto de Investigaciones Jurídicas de la UNAM

mación epigenética del niño así concebido aumentando, por ejemplo, el riesgo de padecer de asma años más tarde. ${ }^{59}$

\section{EN DEFENSA DE UNA REGULACIÓN INTERNACIONAL DE LA GESTACIÓN POR SUSTITUCIÓN A PARTIR DE LA NECESARIA CONSIDERACIÓN \\ DE LOS RIESGOS EPIGENÉTICOS PARA LOS DERECHOS FUNDAMENTALES}

EN JUEGO

Como he venido defendiendo desde el comienzo de estas páginas, la regulación de las cuestiones suscitadas por los avances en las ciencias biomédicas aplicadas a la reproducción humana — de modo especial, la regularización de los derechos-deberes de las partes implicadas en un contrato privado de gestación por sustitución - debe ser internacional. La razón para ello, ya se apuntaba páginas atrás: si se busca su efectividad no debe dejarse margen para santuarios territoriales en los que puedan llevarse a cabo prácticas aberrantes que puedan desplegar efectos jurídicos en el resto de Estados.

Esa regulación internacional debe, además, asumir unos valores superiores que, en nuestra opinión, representan el principio de la dignidad intrínseca del ser humano y las obligaciones internacionales que se derivan del mismo en materia de protección de derechos humanos, en especial, el derecho a la salud, incluyendo la salud reproductiva de los padres de intención, pero también tomando en consideración la salud de la mujer gestante

pp. 171-191. Robertson, J., "Legal Change and Stigma in Surrogacy and Abortion”, The Journal of Law, Medicine \& Ethics, vol. 43, núm. 2, 2015, pp. 192-195; Munro, V., "Surrogacy and the Construction of the Maternal-Foetal Relationship: The Feminist Dilemma Examined”, Res Publica:A Journal of Legal and Social Philosophy, vol. 7, núm. 1, 2001, pp. 13-37. Pande, A., “At Least I Am Not Sleeping with Anyone”, Feminist Studies, vol. 36, núm. 2, 2010, pp. 292-329. De la misma autora: "Not an Angel, not a Whore: Surrogates as «Dirty» Workers in India", Indian Journal of Gender Studies, vol. 16, núm. 2, 2009, pp. 141-173; Majundar, A., "Nurturing an Alien Pregnancy: Surrogate Mothers, Intended Parents and Disembodied Relationships", Indian Journal of Gender Studies, vol. 21, núm. 2, 2014, pp. 199-224; Anu, K. et al., "Surrogacy and Women's Right to Health in India: Issues and Perspective", Indian Journal of Public Health, vol. 57, núm. 2, 2013, pp. 65-70.

59 Kozyrskyj, A. et al., "Continued Exposure to Maternal Distress in Early Life is Associated with an Increased Risk of Childhood Asthma”, Am J Respiratory \& Critical Care Med., núm. 177, 2008, pp. 142 y 143. 
Esta revista forma parte del acervo de la Biblioteca Jurídica Virtual del Instituto de Investigaciones Jurídicas de la UNAM

(madre biológica) y, sobre todo, la salud futura del niño nacido mediante esta técnica a partir de la epigenética.

Considerando la falta de consenso entre los Estados - en parte motivado por los condicionantes éticos y económicos a los que nos referimos al comienzo de nuestro estudio - para una regulación basada en un régimen de protección de derechos humanos de tipo convencional ad hoc para la gestación por sustitución, ${ }^{60}$ se ha planteado por algunos autores apostar por soluciones indirectas en el marco de la Organización Mundial del Comercio (OMC) - considerando el tema desde la perspectiva de la libre prestación de servicios y el principio de la nación más favorecida como límite a las condiciones económicas desiguales entre países desarrollados y en desarrollo cuando celebran estos contratos, a fin de eliminar el turismo reproductivo- ${ }^{61}$

Otros autores, sin embargo, recelan de la vía de la OMC alegando que un creciente número de Estados miembros de esta Organización no son democráticos y en la medida que la $\mathrm{OMC}$ carece de un sistema de requisitos no relacionados con el comercio, tales como la exigencia de que los Estados miembros en dicha Organización respeten y protejan los derechos humanos, la probabilidad de incorporar cuestiones de derechos humanos en el tratamiento de la gestación por sustitución como un supuesto de libre circulación de servicios es muy improbable. ${ }^{62}$

Como vía alternativa para una regulación basada en un régimen de protección de derechos humanos de tipo convencional ad hoc para la gestación por sustitución, se ha propuesto igualmente en los estándares laborales de la Organización Internacional del Trabajo (OIT), considerando el aspecto

60 Se piensa que un instrumento de este tipo probablemente trataría las principales cuestiones en juego mediante estándares muy vagos e indeterminados, más parecido a un soft law con escasa o ninguna repercusión en la práctica. Brugger, K., "International Law in the Gestational Surrogacy Debate”, Fordham International Law Journal, vol. 35, núm. 2, 2012, pp. 685 y 686.

61 Estos autores defienden que la única objeción válida a la gestación por subrogación transfronteriza es que las madres gestantes puedan ser explotadas si reciben muy escasa compensación económica. Así, será éticamente justificada siempre que se practique conforme a las reglas del comercio justo. Humbyrd, C., "Fair Trade International Surrogacy", Developing World Bioethics, vol. 9, núm. 3, 2009, p. 112.

62 Konstatinov, B., "Human Rights and the WTO: Are They Really Oil and Water?", Journal World Trade, vol. 43, 2009, p. 337; Brugger, K., "International Law in the Gestational Surrogacy Debate”, cit., p. 692. 
Esta revista forma parte del acervo de la Biblioteca Jurídica Virtual del Instituto de Investigaciones Jurídicas de la UNAM

"laboral" de la mujer gestante a pesar de que sus condiciones laborales (24 horas al día durante todo el periodo de gestación) lo aproximan más a una relación de esclavitud que a un trabajo. La principal crítica que se realiza a esta propuesta es que el mandato relativamente limitado de la OIT podría excluir del ámbito de su protección al niño nacido mediante el contrato de gestación por sustitución, así como ignorar algunas de las auténticas barreras que — afectando a esos niños - impiden un tratamiento homogéneo de la prestación de este servicio reproductivo, tales como las normas sobre inmigración y ciudadanía. ${ }^{63}$

Se ha defendido también la regulación indirecta a través de una agencia internacional encargada de verificar el cumplimiento de estándares internacionales de acreditación por parte de las empresas que presten servicios de gestación por sustitución, bastando a tal fin con incorporarla a la Convención de la Haya sobre Adopción Internacional de 1993. ${ }^{64}$ Como reconocen los autores de esta propuesta, el principal obstáculo a la misma reside en el hecho de que muchos países europeos que son parte en dicha Convención sobre Adopción Internacional no permiten en sus legislaciones internas la gestación por sustitución con carácter comercial. ${ }^{65}$

Al igual que sucede en otros ámbitos de los avances de las ciencias de la vida, los crecientes esfuerzos por parte de la comunidad científica en desarrollar la investigación en epigenética plantea importantes cuestiones desde el punto de vista jurídico y ético. A los efectos de este trabajo nos hemos centrado sólo en un aspecto de la epigenética relacionada con la gestación por sustitución; en concreto, hemos pretendido plantear diversos elementos para una reflexión en relación con los riesgos epigenéticos para la salud del niño nacido mediante la técnica de gestación sustitutoria y esto con la intención de reforzar la tesis de que dicha gestación requiere de una regulación internacional que debe hacerse desde el bioderecho internacional. ${ }^{66}$

Esto es, desde una aproximación normativa internacional — no sólo nacional o de derecho comparado- - que sea transversal — considerando to-

63 Brugger, K., "International Law in the Gestational Surrogacy Debate”, cit., p. 696.

64 Davis, E., "The Rise of Gestational Surrogacy and the Pressing Need for International regulation”, Minnesota Journal of International Law, vol. 21, núm. 1, 2012, p. 142.

65 Idem.

66 Véase, sobre el tema, García San José, D. "Epygenetic: New Challenges for Fundamental Rights”, Ius Et Scientia, vol. 1, núm. 1, 2015, pp. 79-92, disponible en: http: / / institucional/ us.es/iusetscientia. 
Esta revista forma parte del acervo de la Biblioteca Jurídica Virtual del Instituto de Investigaciones Jurídicas de la UNAM

das las vertientes jurídicas en juego y, en particular, la dimensión de los derechos humanos - e integradora, en el sentido de que asuma como marco de discusión para dicha regulación unos parámetros que no sean maximalistas ni maniqueos — de defensores y detractores a ultranza de las nuevas técnicas de reproducción asistida-, sino convergentes hacia posiciones de consenso. En este sentido, creo que la mejor expresión de dicha aproximación integradora es la teoría del justo equilibrio de los distintos intereses en juego, como viene desarrollando desde hace décadas el Tribunal Europeo de Derechos Humanos al interpretar y aplicar los derechos y libertades reconocidos en el Convenio Europeo de Derechos Humanos.

\section{A MODO DE INSPIRACIÓN PARA EL LEGISLADOR INTERNACIONAL: UN INSTRUMENTO CONVENCIONAL DE PROTECCIÓN DE LOS DERECHOS HUMANOS AD HOC PARA LA GESTACIÓN POR SUSTITUCIÓN} QUE TOME EN CONSIDERACIÓN TODOS LOS INTERESES EN JUEGO A PARTIR DE LA EXPERIENCIA DEL TRIBUNAL EUROPEO DE DERECHOS HuMANOS

En las próximas páginas presentaré sucintamente los últimos desarrollos en la doctrina del justo equilibrio entre los diferentes intereses en juego, ${ }^{67}$ tal como la ha aplicado el Tribunal Europeo de Derechos Humanos en sus sentencias del 26 de junio de 2014 (Casos Labasse y Menesson con Francia) y del 27 de enero de 2015 (Caso Paradiso y Campanelli contra Italia), salvo error por mi parte, los únicos casos decididos hasta la fecha en relación con la gestación por sustitución. Ninguno de los dos presenta en sus hechos ni en sus fundamentos jurídicos, referencias a los riesgos epigenéticos, lo cual no afecta a su invocación en este trabajo. Como ya señalé en la introducción de este artículo, la referencia a la jurisprudencia del Tribunal Europeo de Derechos Humanos sirve para explicar porqué la doctrina del justo equilibrio de los diferentes intereses en juego me parece la piedra angular de un eventual régimen convencional ad hoc de protección de derechos humanos, aplicado a la gestación por sustitución en la medida en que serviría para

67 Sobre la cuestión más desarrollada puede verse el capítulo 5 de García San José, D., International Bio Law. An International Overview of Developments in Human Embryo Research and Experimentation, Murcia, Laborum, 2010, disponible en: http://institucional.us.es/bioderinter. 
considerar todos los aspectos de esta cuestión: los intereses económicos de sociedades de países como India que son destino preferente del turismo reproductivo, los condicionantes éticos de quienes se oponen a estas técnicas por trivializar el principio de la dignidad humana, los intereses políticos de los gobiernos que cuentan con sus propias normas de filiación y de concesión de ciudadanía, de una parte, y los derechos humanos, de otra: el derecho a la salud reproductiva de los padres de intención, el derecho a desarrollar libremente una actividad remunerada sin sufrir explotación en el caso de la madre biológica y el derecho al respeto de su dignidad y a no sufrir riesgos en su salud, en el caso del niño concebido mediante gestación por sustitución.

\section{Los Casos Labassee y Mennesson contra Francia}

Los dos casos son muy similares en cuanto a sus hechos: sendos matrimonios de nacionalidad francesa que no pudiendo tener hijos por causa de infertilidad de la mujer, acudieron a los servicios de una empresa de gestación por sustitución en California, donando los varones sus gametos y usando óvulos de una donante anónima que fue fecundado e implantado en una madre gestante. Como resultado del proceso, nacen dos gemelas para los Mennesson y una niña para los Labassee. ElTribunal Supremo de California declaró la paternidad legal de los padres de intención con el consentimiento de todas las partes implicadas y al acudir al Consulado francés en los Ángeles solicitando la transcripción del acta de nacimiento y la inscripción de las niñas en sus pasaportes para poder entrar con ellas en Francia, sendos matrimonios recibieron por respuesta una negativa de las autoridades consulares al sospechar que estaban ante dos casos de gestación por sustitución prohibido por la legislación gala. Con pasaporte norteamericano para las niñas y francés de los progenitores, regresaron a Francia e iniciaron un proceso judicial sin éxito antes de acudir al Tribunal Europeo de Derechos Humanos (en adelante, TEDH).

El 26 de junio de 2014, el TEDH resolvió, por unanimidad, ambos casos declarando que Francia era responsable de una violación del artículo 8o. del Convenio al no haber permitido que los demandantes pudieran inscribir en el Registro Civil a sus hijas nacidas mediante un contrato privado de gestación por sustitución que habían celebrado en California. 
Esta revista forma parte del acervo de la Biblioteca Jurídica Virtual del Instituto de Investigaciones Jurídicas de la UNAM

En su razonamiento, el TEDH comenzó recordando lo ya reiterado con anterioridad (por ejemplo, en su sentencia en el casoWagner y J. M.W.L.contra Luxemburgo, del TEDH del 1o. de abril de 2010, pará. 117): para garantizar el derecho al respeto a la vida privada y familiar, el artículo 8o. del Convenio Europeo de Derechos Humanos presupone la existencia de una familia, pudiendo ser los vínculos familiares "de facto", ${ }^{68}$ situación que se daba en ambos casos pues el TEDH reconoció que tanto los Mennesson como los Labassee se ocuparon de sus hijos como padres desde su nacimiento, viviendo de un modo que en nada se distingue de la vida familiar en su acepción habitual.

Tras constatar que el artículo 8o. del Convenio entraba en juego, procedió a valorar si la injerencia en los derechos reconocidos en dicho artículo, el derecho al respeto de la vida familiar y el derecho al respeto de la vida privada era o no conforme a lo que exige el párrafo segundo de dicho artículo: que sea una injerencia prevista en la ley, que persiga un fin legítimo en una sociedad democrática y que se respete una relación de proporcionalidad entre el fin perseguido y la injerencia sufrida por el particular en el ejercicio de sus derechos.

Para constatar la proporcionalidad de la injerencia, el TEDH valora una serie de circunstancias en cada caso que conoce, a fin de reconocer un mayor o menor margen de apreciación a los Estados, estableciendo el siguiente silogismo: cuando un amplio margen de apreciación debe ser reconocido a los Estados, el TEDH debe mostrar una autolimitación judicial no pretendiendo sustituir a la autoridades nacionales en la valoración de las medidas adoptadas en una sociedad democrática para alcanzar el fin legítimo perseguido. Por el contrario, cuando a la luz de los factores relevantes del caso, el TEDH entiende que debe reconocer un margen de apreciación nacional reducido, la conclusión es al contrario: procede a mostrar un activismo judicial pro víctima de la injerencia en el ejercicio de los derechos reconocidos de manera que sólo razones particularmente relevantes serán suficientes para justificar la compatibilidad de la injerencia con las obligaciones derivadas del Convenio. En los Casos Labassee y Mennesson contra Francia, el TEDH comenzó recordando la falta de consenso en la materia que abogaba

68 Parágrafo 45 de la sentencia del TEDH del 26 de junio de 2014 en el Caso Mennesson c. Francia; parágrafo 81 de la sentencia del TEDH del 26 de junio de 2014, en el Caso Labassee c. Francia. 
Esta revista forma parte del acervo de la Biblioteca Jurídica Virtual del Instituto de Investigaciones Jurídicas de la UNAM

en principio por reconocer un amplio margen de apreciación nacional a las autoridades francesas. ${ }^{69}$ Sin embargo, elTEDH valoró la naturaleza del derecho en juego y su importancia para los particulares afectados por la injerencia. A tal fin, el TEDH distingue la situación de los padres de la de los hijos.

Así, en el supuesto de los padres, la injerencia sufrida estaría justificada por las razones de orden público invocadas por las autoridades francesas pues, aunque implicaba una serie de consecuencias negativas para su vida diaria, no les impedía en ningún caso el establecimiento de una vida familiar. Las dificultades no eran insuperables y podían vivir en condiciones equiparables a las que viven otras familias. ${ }^{70}$ En cambio, tratándose de las hijas, el hecho de que un aspecto esencial de su identidad está en juego cuando como en las circunstancias de ambos casos_ — está afectada la filiación, hace que el margen de apreciación se reduzca considerablemente hasta el punto de que elTEDH no considere justificada la injerencia sufrida por las hijas. ${ }^{71}$

Respecto de la situación de las hijas - la injerencia sufrida en su derecho al respeto de su vida privada_-, el TEDH entiende que el respeto de este derecho se vincula con la esencia de la identidad, incluyendo su filiación, la cual se había visto afectada de manera significativa en ambos casos. Recordando que en ambos casos el donante de gametos masculino era el padre de intención, el TEDH declaró que la paternidad biológica forma parte de la identidad del individuo de manera que la prohibición de la gestación por sustitución existente en un Estado parte en el Convenio no puede provocar el desconocimiento de su filiación y así proyectarse sobre la identidad de las niñas, a las que se sitúa en una situación de incertidumbre jurídica sobre su identidad. Lo mismo ocurría con el derecho a la nacionalidad en la medida en que la nacionalidad constituye un elemento de la identidad de las personas. A mayor abundamiento en este análisis, el TEDH resalta el hecho del lazo biológico del padre de intención y las niñas. ${ }^{72}$

69 Parágrafo 45 de la sentencia del TEDH del 26 de junio de 2014 en el Caso Mennesson c. Francia; parágrafo 81 de la sentencia del TEDH del 26 de junio de 2014, en el Caso Labassee c. Francia.

70 Parágrafos 78 y 79 de la sentencia del TEDH del 26 de junio de 2014 en el Caso Mennesson c. Francia.

71 Parágrafos 96 a 98 de la sentencia del TEDH del 26 de junio de 2014 en el Caso Mennesson c. Francia; parágrafos 79 a 81 de la sentencia del TEDH del 26 de junio de 2014, en el Caso Labassee c. Francia.

72 Parágrafos 100 a 102 de la sentencia del TEDH del 26 de junio de 2014 en el Caso Men- 
Esta revista forma parte del acervo de la Biblioteca Jurídica Virtual del Instituto de Investigaciones Jurídicas de la UNAM

Ahora bien, en la gestación por sustitución no siempre se da dicho vínculo biológico entre los padres de intención y el menor nacido mediante un contrato de este tipo. ¿Serían aplicables los principios enunciados por elTEDH en las sentencias dictadas en los Casos Labassee y Mennesson a otros supuestos en los que faltara dicho vínculo biológico? La más reciente sentencia dictada en Sala por el TEDH en el Caso Paradiso y Campanelli contra Italia el 27 de enero de 2015 —pendiente de ser resuelta con carácter definitivo por la Gran Sala del TEDH - puede ilustrarnos a este respecto. ${ }^{73}$

\section{El Caso Paradiso y Campanelli contra Italia}

A diferencia de los casos antes citados, en el Caso Paradiso y Campanelli contra Italia no existía un vínculo biológico entre ninguno de los padres de intención y un niño nacido mediante un contrato de gestación por sustitución concluido por estos y una empresa en Rusia. En opinión del TEDH, la existencia o no de vida familiar es esencialmente una cuestión fáctica que dependerá de la existencia real en la práctica de estrechos lazos personales. Profundizando más, la noción de "familia" en el artículo 8o. no está confinada sólo a relaciones basadas en un matrimonio, pudiendo comprender otros "vínculos familiares" de facto cuando las partes están viviendo juntas fuera de un matrimonio y la relación tiene suficiente consistencia. ${ }^{74}$ Aun cuando el artículo 8o. del Convenio Europeo de Derechos Humanos no garantiza

nesson c. Francia; parágrafos 79 a 81 de la sentencia del TEDH del 26 de junio de 2014, en el Caso Labassee c. Francia.

73 A esos casos habría que sumar otros cuando se dicten en su día, no antes de dos años, sentencias en las demandas pendientes: Laborie c. Francia (núm. 44024/13) relativo a la imposibilidad para una pareja francesa de ver reconocido en Francia la relación paterno-filial entre ellos y los niños nacidos en Ukrania mediante un contrato de gestación por sustitución. Foulon c. Francia (núm. 9063/14) y Bouvet c. Francia (núm. 10410/14), relativos a la imposibilidad de un nacional francés de obtener el reconocimiento de Francia de la relación paterno-filial entre él y un niño nacido en la India mediante un contrato de estación por sustitución.

74 Parágrafo 67 de la sentencia del TEDH del 27 de enero de 2015 en el Caso Paradiso y Campanelli contra Italia. Véase la jurisprudencia citada en la misma a este respecto: Caso Kroon y Otros contra Holanda, sentencia del TEDH del 27 de octubre de 1994, pará. 30; Caso Johnston y Otros c. Irlanda, sentencia del TEDH del 18 de diciembre de 1986, pará. 55; Caso Keegan c. Irlanda, sentencia delTEDH del 18 de diciembre de 1986, para. 44; Caso X,Y y Z c. Reino Unido, sentencia del TEDH del 22 de abril de 1997, pará. 36. 
Esta revista forma parte del acervo de la Biblioteca Jurídica Virtual del Instituto de Investigaciones Jurídicas de la UNAM

ni el derecho a fundar una familia ni el derecho a adoptar, el derecho al respeto de la vida familiar — reconocido en dicho artículo - presupone la existencia de una familia, o al menos, la relación potencial entre un menor y unos adultos, que surge, por ejemplo, de un genuino matrimonio incluso si la vida familiar no ha sido aún plenamente establecida, o la relación que surge de una adopción legal. Recordó, en este sentido, el Caso Moretti y Benedetti contra Italia, relativo a un matrimonio (los demandantes) que había aceptado acoger dentro de su familia a una niña de un año de edad. Aun cuando sólo estuvieron 19 meses con ella, hasta que los tribunales italianos decidieron entregarla a otra familia en adopción, el TEDH concluyó en dicho caso que existía una vida familiar de facto. ${ }^{75}$

Para elTEDH existía una familia de facto en el Caso Paradiso y Campanelli contra Italia, entre otras razones, considerando que los demandantes habían compartido con el niño las primeras importantes etapas de su joven vida: seis meses en Italia, desde el tercer mes de vida de éste. Antes de ese periodo, el primer demandante había pasado varias semanas junto al niño en Rusia. Aunque ese periodo fuera en sí mismo relativamente corto, el Tribunal consideró que los demandantes habían actuado como padres con el niño y concluyó que existía una vida familiar de facto entre los demandantes y el niño. ${ }^{76}$ Es de especial importancia que en el parágrafo 70 de su sentencia expresamente constate que no existe una relación genética entre el segundo demandante y el niño. Aun así, el TEDH reiteró que el artículo 8o. protege no sólo la vida familiar, sino también la vida privada. Esto incluye, hasta cierto punto, el derecho a establecer relaciones con otros. ${ }^{77}$

ElTEDH expresó la opinión de que no existen razones para creer que la noción de vida privada sea usada en el sentido de excluir la determinación de una relación legal o biológica entre un niño nacido fuera del matrimonio y su padre natural, habida cuenta de que el TEDH ha venido sosteniendo que el respeto de la vida privada exige que cada uno sea capaz de establecer detalles de su identidad como ser humano, y que esa información es de

75 Sentencia del TEDH del 27 de enero de 2015 en el Caso Paradiso y Campanelli c. Italia, para. 68. Caso Moretti y Benedetti c. Italia, sentencia del TEDH del 27 de abril de 2010, paras. 50 a 52.

76 Caso Paradiso y Campanelli c. Italia, sentencia del TEDH del 27 de enero de 2015, pará. 69.

77 Como ya señaló, por ejemplo, en el Caso Niemtiz c.Alemania, sentencia del TEDH del 16 de diciembre de 1992, pará. 29. 
Esta revista forma parte del acervo de la Biblioteca Jurídica Virtual del Instituto de Investigaciones Jurídicas de la UNAM

importancia para el individuo a causa de las implicaciones para su personalidad. ${ }^{78}$

Una vez constatada la aplicación del artículo 8o. del Convenio a las circunstancias del caso, ya que se daba unos vínculos familiares de facto entre los padres de intención y el niño nacido en Rusia pese a no existir vínculo biológico entre ellos, el TEDH procedió a examinar si la injerencia de las autoridades italianas podía ser constitutiva de una violación de los derechos reconocidos a los demandantes en dicho artículo 8o. del Convenio.

Las injerencias en los artículos 8o. a 11 del Convenio deben superar los requisitos previsto en el párrafo segundo común a dichos artículos: ser una injerencia prevista en la ley, perseguir un fin legítimo y ser una injerencia necesaria en una sociedad democrática, lo que implica el respetar un justo equilibrio entre los distintos intereses en juego, esto es, entre los derechos de los demandantes y entre los fines perseguidos por las autoridades nacionales y los medios empleados para conseguirlos. Para resolver en el presente caso la cuestión relativa a si la aplicación de la ley por las autoridades italianas respetó un justo equilibrio entre el interés público y los intereses privados en juego, elTEDH asume que debe considerar el principio esencial según el cual siempre que esté en juego la situación de un niño, lo principal es salvaguardar el interés superior del menor. ${ }^{79}$ Así, aun cuando ha quedado establecido que el padre de intención no tenía vínculo genético alguno con el niño gestado mediante un contrato de sustitución, ${ }^{80}$ la apli-

78 Véase el Caso Gaskin c. Reino Unido, sentencia del TEDH del 7 de julio de 1989, para. 39. En el Caso Paradiso y Campanelli contra Italia, el segundo demandante perseguía establecer, por sentencia judicial, que era padre natural del niño. Esta solicitud de reconocimiento de su paternidad, había sido legalmente establecida en Rusia pero en Italia se condicionó a un test de identidad biológica, buscando descubrir si existía o no un vínculo biológico con el niño. El test dio negativo; sin embargo, en opinión del TEDH existía un vínculo directo entre el establecimiento de la paternidad y el derecho a la vida privada del segundo demandante, con lo cual, el artículo 8o. del Convenio entraba en consideración.

79 Caso Paradiso y Campanelli contra Italia, sentencia del TEDH de 27 de enero de 2015, pará. 74; Caso Wagner y J.M.W.L contra Luxemburgo, sentencia del TEDH de 1 de abril de 2010, parás. 133-134; Caso Mennesson c. Francia, sentencia del TEDH de 26 de junio de 2014, pará. 81; Caso Labassee c. Francia, sentencia del TEDH de 26 de junio de 2014, para. 60.

80 Caso Paradiso y Campanelli contra Italia, sentencia del TEDH del 27 de enero de 2015, pará. 76. De conformidad con la legislación rusa al menos uno de los padres de intención debía tener un vínculo genético con el niño gestado por sustitución. En este caso, la empresa privada que preparó todo compró gametos y óvulos de donantes anónimos con lo cual ese embrión (fecundado in vitro y alojado en la madre gestante pasaba ser "el embrión" de los pa- 
Esta revista forma parte del acervo de la Biblioteca Jurídica Virtual del Instituto de Investigaciones Jurídicas de la UNAM

cación de la ley italiano produjo como resultado el no reconocimiento de la relación de parentesco legal establecida en el extranjero debido a que los demandantes no tenían ningún vínculo biológico con el niño, y al respecto el TEDH considera que los tribunales nacionales no han actuado de manera irrazonable al aplicar estrictamente la ley para determinar la paternidad y al ignorar el estatus legal establecido en el extranjero. ${ }^{81}$

Ahora bien, aún queda por determinar si, en esta situación, las medidas tomadas con respecto al niño, en particular, su retirada de los demandantes y su entrega en acogida por otra familia puede ser considerada una medida proporcionada, queda por ver si los intereses del niño fueron tomados en consideración de manera suficiente por las autoridades italianas. A ese respecto, el TEDH sostuvo la opinión de que las referencias al orden público (como fin legítimo) no pueden ser consideradas como que confieren carta blanca para cualquier medida, ya que el Estado tiene una obligación de tomar en consideración el interés superior del menor, con independencia de la naturaleza del vínculo parental, genético o de otro tipo. ${ }^{82}$ En este caso concreto, la decisión de las autoridades italianas de retirarles el niño nacido mediante gestación por sustitución, no puede considerarse una medida justificada en opinión delTEDH, por las razones que enumera en los parágrafos 82 a 85 de su sentencia:

- En primer lugar, el alegar que el niño habría desarrollado lazos emocionales más estrechos con sus padres de intención, en caso de que le hubiera permitido estar más tiempo con ellos, no justifica su retirada.

- Con respecto a la causa penal traída contra los demandantes, el TEDH constató que el Tribunal de Apelación italiano había mantenido que no era necesario esperar a su resultado ya que la responsabilidad penal de los demandantes era insignificante, de manera que las sospechas que pe-

dres de intención. De hecho el padre de intención estaba convencido de ser el padre biológico del niño y no se ha podido probar que actuase de mala fe.

81 Caso Paradiso y Campanelli c. Italia, sentencia del TEDH del 27 de enero de 2015, pará. 77.

82 Ibidem, pará. 80. Confirmando su reciente jurisprudencia en este punto: el retirar un niño de una familia es una medida que sólo puede estar justificada si persigue como fin el proteger al niño frente a un peligro inmediato que lo amenaza: Caso Y. C. contra Reino Unido, sentencia delTEDH del 13 de marzo de 2012, parás. 133 a 138; Caso Pontes c. Portugal, sentencia del TEDH del 10 de abril de 2012, parás. 74-80. 
Esta revista forma parte del acervo de la Biblioteca Jurídica Virtual del Instituto de Investigaciones Jurídicas de la UNAM

saban sobre los demandantes eran también insuficientes para justificar la medida controvertida.

- El TEDH observó que los demandantes, que habían sido catalogados como aptos para adoptar en diciembre de 2006, cuando recibieron la autorización para ello, fueron hallados incapaces de criar y amar al niño sólo sobre la base de que se habían saltado el procedimiento de adopción, sin que los tribunales italianos hubieran encargado ningún informe de expertos al respecto.

- Por último, el TEDH señaló que el niño recibió una nueva identidad a partir de abril de 2013, lo que significa que no tuvo identidad oficial durante más de dos años. Sin embargo, es necesario asegurar que un niño no esté en situación desventajosa por el hecho de que haya nacido de una madre que lo haya gestado por sustitución, especialmente, en términos de ciudadanía o de identidad, que son de crucial importancia (como prevé el artículo 7o. de la Convención de Naciones Unidas sobre los Derechos del Niño del 20 de noviembre de 1989).

En consecuencia, no estando el TEDH convencido de las razones que motivaron a las autoridades italianas para concluir la necesidad de que el niño pasara a los cuidados de los servicios sociales, concluyó que fallaron a la hora de respetar un justo equilibrio entre los intereses en presencia causando una violación del artículo 8o. del Convenio. ${ }^{83}$

La conclusión que puede extraerse de lo comentado en este epígrafe podría ser, por un lado, que la perspectiva iusinternacionalista desde la protección internacional de los derechos humanos parece confirmarse como la más idónea y conveniente para abordar las diversas cuestiones que suscita la práctica de los contratos privados de gestación por sustitución. La aproximación nacional no me parece siempre válida porque aun cuando generalmente considera como prevalente el interés superior del menor, lo hace admitiendo diversos grados de protección frente a otros intereses a los que llega en algunos casos dicho interés a ceder, ${ }^{84}$ situación que, como se ha

83 Caso Paradiso y Campanelli c. Italia, sentencia del TEDH del 27 de enero de 2015, pará. 87 .

84 Así lo han destacado cuatro magistrados en su voto particular discrepante con la mayoría en el Auto del Tribunal Supremo de España, del 2 de febrero de 2015, dictado en el incidente de nulidad de actuaciones formulado contra la sentencia del 6 de febrero de 2014, por el que dicho Tribunal niega cualquier incidencia en el ordenamiento jurídico español de 
visto, no asume como válida el Tribunal Europeo de Derechos Humanos, y pienso que tampoco lo hará la Corte Interamericana de Derechos Humanos en la primera ocasión en que tenga que pronunciarse sobre un caso relativo a gestación por sustitución. Siguiendo la teoría del justo equilibrio de los diferentes intereses en juego, me parece pertinente disociar los derechos de los padres de intención y de la mujer gestante, por una parte, y los derechos a la integridad física y psíquica del menor nacido mediante esta técnica, así como su derecho a la identidad personal, por otra parte. De este modo, consideraciones de orden público pueden prevalecer sobre el pretendido derecho a ser progenitor, cuando biológicamente se está impedido para crear una familia. Sin embargo, frente a los derechos del menor, deben ceder las razones que, por muy legítimas que sean, inciden de manera injustificada en su normal desarrollo como persona.

En definitiva, un régimen convencional de protección de derechos humanos ad hoc para la gestación por sustitución, que tome la teoría del justo equilibrio entre los distintos intereses en juego no sólo servirá para que el derecho asuma nuevas formas de familia conforme los avances de la ciencia para hacer de derecho lo que ya es de hecho. Además, y sobre todo, permitirá hacer frente a los incesantes riesgos que estos avances nos plantean como seres humanos individuales y como especie.

\section{A MODO DE CONCLUSIONES PROVISIONALES}

Primera. El negocio global de la gestación por sustitución y el turismo reproductivo asociado al mismo requiere una regulación que ha de ser internacional si se quiere efectiva, no dando lugar a santuarios territoriales en los que puedan llevarse a cabo prácticas aberrantes que puedan desplegar efectos jurídicos en el resto de Estados. Desde el punto de vista del derecho internacional privado, hasta la fecha se ha trabajado y se continua haciendo, a fin de responder a la cuestión de si un Estado estaría o no obligado a reconocer la filiación legal establecida en el extranjero de un niño nacido

las sentencias del Tribunal Europeo de Derechos Humanos en los Casos Menesson y Labasse contra Francia. Son los magistrados José Ramón Ferrándiz Gabriel, José Antonio Seijas Quintana, Francisco Javier Arroyo Fiestas y Sebastián Sastre Papiol. 
Esta revista forma parte del acervo de la Biblioteca Jurídica Virtual del Instituto de Investigaciones Jurídicas de la UNAM

mediante un contrato de gestación por sustitución con sus padres de intención con los que no tiene un vínculo genético.

Siendo relevante y necesaria una aproximación jurídica a cuestiones como la filiación o la nacionalidad en conexión con la gestación por sustitución, en mi opinión, no es la más urgente ni la principal si nos ubicamos en un discurso centrado en la protección internacional de los derechos humanos. El autor de este artículo piensa, por el contrario, que el principio del respeto de la dignidad humana y la obligación internacional de proteger los derechos humanos de las partes más vulnerables en los contratos privados de gestación por sustitución - la mujer gestante y el niño que engendrason referentes esenciales en la regulación internacional de la gestación por sustitución.

Segunda. Desde el punto de vista de los derechos humanos, la necesidad de una regulación internacional de tipo convencional ad hoc para la gestación por sustitución pretende dar solución a cuestiones diversas. Por una parte, se invoca el derecho humano a la salud reproductiva, incluyendo la capacidad de procrear sin riesgos gracias a los avances en las técnicas de reproducción asistida. Por otra parte, la necesidad de una regulación internacional responde al deseo de evitar la explotación de mujeres pobres o económicamente vulnerables que se prestan a alquilar sus vientres e, incluso, a donar sus propios óvulos.

Ahora bien, desde el discurso de los derechos humanos cada vez más voces reclaman prestar mayor atención a los derechos de los niños - la más sensible de las dos más vulnerable partes en un contrato de gestación por sustitución - en la medida en que al no existir éstos en el momento de la celebración del contrato, no se puede exigir su consentimiento, con lo cual su estatus se asemeja más al de "producto" resultante del mismo, con grave riesgo para su dignidad al tratar como mercancía la vida humana. Este riesgo se ha demostrado real en aquellos casos en los que el bebé nacido mediante esta técnica ha sido rechazado como "defectuoso" por los padres de intención.

En este sentido, salvo error por mi parte, hasta la fecha no se ha considerado la epigenética al hablar del interés superior del menor en el contexto de la gestación por sustitución, de ahí la pertinencia del análisis que hemos desarrollado en esta comunicación - centrado en el examen de los riesgos epigenéticos derivados de la gestación por sustitución para la salud del niño así concebido - y reclamando una regulación internacional desde la pers- 
pectiva de los derechos humanos para este negocio sin fronteras que sustituya el todo poderoso laissez faire, laissez passer, imperante en la actualidad.

Tercera. La regulación internacional que considero en este artículo como la más idónea para abordar los problemas apuntados, a pesar de su aparente ingenuidad, es la de un convenio de protección de derechos humanos ad hoc para la gestación por sustitución, que tome en consideración la protección de los derechos de los padres de intención y de la madre biológica junto con el derecho a la salud del niño así concebido frente a los eventuales riesgos epigenéticos para su salud. A tal fin se propone como fuente inspiradora para el legislador internacional la teoría del justo equilibrio de los distintos intereses en juego, como viene desarrollando desde hace décadas el Tribunal Europeo de Derechos Humanos y ha aplicado recientemente en sus sentencias del 26 de junio de 2014 (Casos Labasse y Menesson con Francia) y del 27 de enero de 2015 (Caso Paradiso y Campanelli contra Italia), las únicas hasta la fecha decididas en relación con la gestación por sustitución y el interés superior del menor. Aun cuando las cuestiones epigenéticas no se planteaban en dicha jurisprudencia, su tratamiento ha servido para reforzar la idea de que el interés superior del menor sea considerado en dicha eventual regulación convencional ad hoc no sólo en relación con su derecho a la identidad como parte de su vida privada, sino especialmente en atención a la efectiva protección de su derecho a la salud.

VII. BIBLIOGRAFÍA

Abrams, P., “The Bad Mother. Stigma, Abortion and Surrogacy”, The Journal of Law, Medicine \& Ethics, vol. 43, núm. 2, 2015.

AgnAfors, M., "The Harm Argument Against Surrogacy Revisited: Two Versions not to Forget", Medicine, Health Care and Philosophy, vol. 17, núm. 3, 2014.

Ainsworth, S., "Bearing Children, Bearing Risks: Feminist Leadership for Progressive Regulation of Compensated Surrogacy in the United States", Washington Law Review, vol. 89, núm. 4, 2014.

ANU, K., et al., "Surrogacy and Women's Right to Health in India: Issues and Perspective”, Indian Journal of Public Health, vol. 57, núm. 2, 2013. 
Esta revista forma parte del acervo de la Biblioteca Jurídica Virtual del Instituto de Investigaciones Jurídicas de la UNAM

Beaumont, P. y Trimmings, K., "Recent Jurisprudence of the European Court of Human Rights in the Area of Cross-border Surrogacy: Is there Still a Need for Global Regulation of Surrogacy?”, en BAGIONI, G. et al., Migrant Children in the XXI Century. Selected Issues of Public and Private International Law, 2016, Editoriale Scientifica (en prensa).

Brennan, J. y Capel, B., "One Tissue, Two Fates: Molecular Genetic Events that Underlie Testis Versus Ovary Development”, Nature Rev Genetics, núm. 5, 2004.

BRUGGer, K., "International Law in the Gestational Surrogacy Debate", Fordham International Law Journal, vol. 35, núm. 2, 2012.

BRUnet, L., "La Globalization Internationale de la Gestation Pour Autrui", Travail, Genre et Societés, núm. 2, 2012.

Casado Blanco, M. e IbáÑEZ Bernáldez, M., "Reflexiones legales y éticas en torno a la maternidad subrogada", Revista Española de Medicina Legal, vol. 40, núm. 2, 2014.

Conferencia Internacional De Derecho Internacional Privado De La Haya (HCCH), The Parentage/Surrogacy Project: an Updating Note, febrero de 2015, disponible en: https://assets.hcch.net/docs/82d31f31-294 f-47fe-9166-4d9315031737.pdf.

Cooney, G., "Germ Cells Carry the Epigenetic Benefits of Grandmother's Diet”, Proc. Nat'l Acad Sci, núm. 103, 2006.

DAGAR, T., et al., "Surrogacy in India: Current Scenario", Indian Journal of Health andWellbeing, vol. 6, núm. 5, 2015.

Davis, E., "The Rise of Gestational Surrogacy and the Pressing Need for International Regulation”, Minnesota Journal of International Law, vol. 21, núm. 1, 2012.

DeOnandan, R. et al., "Ethical Concern for Maternal Surrogacy and Reproductive Tourism”, Journal of Medical Ethics, vol. 38, núm. 12, 2012.

Dolinoy, D. et al., "Epigenetic Gene Regulation: Linking Early Developmental Environment to Adult Disease”, Reproductive Toxicology, núm. 23, 2007 .

DrabiaK, K. et al., "Ethics, Law and Commercial Surrogacy: a Call for Uniformity”, The Journal of Law, Medicine \& Ethics, vol. 35, núm. 2, 2007.

Ekberg, M., "Ethical, Legal and Social Issues to Consider when Designing a Surrogacy Law”, Journal of Law and Medicine, vol. 21, núm. 3, 2014.

EGger, G., et al., "Epigenetics in Human Disease and Prospects for Epigenetic Therapy”, Nature, núm. 429, 2004. 
Esta revista forma parte del acervo de la Biblioteca Jurídica Virtual del Instituto de Investigaciones Jurídicas de la UNAM

Ettinger, D., "Genes, Gestation and Social Norms", Law and Philosophy:An International Journal for Jurisprudence and Legal Philosophy, vol. 31, núm. 2, 2012.

FeinberG, A., "Epigenetics at the Epicenter of Modern Medicine", 299 JAMA, 2008.

FENTON-GlynN, C., "Outsourcing Ethical Dilemmas: Regulating International Surrogacy Arrangements”, Medical Law Review, vol. 24, núm. 1, 2016.

Gallou-Kabani, C. et al., "Nutri-epigenomics: Lifelong Remodeling of our Epigenomes by Nutritional and Methabolic Factors and Beyond", Clinical Chemistry \& Laboratory, núm. 45, 2007.

García Robles, R. et al., "Epignética: definición, bases moleculares e implicaciones en la salud y en la evolución humana”, Revista Ciencias de la Salud, vol. 10, núm. 1, 2012.

GARCÍA SAN JOSÉ, D. , "Epygenetic: new challenges for fundamental rights", Ius Et Scientia, vol. 1, núm. 1, 2015, disponible en: http://institucional/ us.es/iusetscientia.

, International Bio Law. An international overview of developments in human embryo research and experimentation, Murcia, Laborum, 2010, disponible en: http://institucional.us.es/bioderinter.

(coord.), European Normative Framework for Biomedical Research in Human Embryos, Thomson-Reuter Aranzadi, 2013, Cizur menor.

GonzÁlez Martín, N. y Albornoz, Ma. M., "Aspectos transfronterizos de la gestación por sustitución”, Anuario Mexicano de Derecho Internacional, vol. XVI, 2016, disponible en: http: / / www2.juridicas.unam.mx/ 2016/01/28/aspectos-transfronterizos-de-la-gestación-por-sustitucion.

Gorman, R., "The New Hereditary”, Protomag, 2007, disponible en: http: / / protomag.com/issues /2007_fall / pdfs / hereditary.pdf.

HOWARD, S., "Proposed Ban on Foreigners Using India Surrogacy Services Sparks Protests”, British medical Journal, 2 de noviembre de 2015, núm. 351-353.

JirTle, R. y Skinner, M., "Environmental Epigenomics and Disease Susceptibility”, Nature Rev Genetics, vol. 8, 2007.

KonstatinOv, B., "Human Rights and the WTO: Are They Really Oil and Water?", Journal World Trade, vol. 43, 2009. 
Esta revista forma parte del acervo de la Biblioteca Jurídica Virtual del Instituto de Investigaciones Jurídicas de la UNAM

KozyrskyJ, A., et al., "Continued Exposure to Maternal Distress in Early Life is Associated with an Increased Risk of Childhood Asthma”, Am J Respiratory \& Critical Care Med., 2008, núm. 177.

MAHER, E., et al., "Epigenetic Risks Related to Assisted Reproductive Technologies: Epigenetics, Imprinting, ART and Icebergs?", Human Reproduction, vol. 18, núm. 12, 2003.

MCMillan, J., "Making sense of Child Welfare When Regulating Human Reproductive Technologies", Journal of Bioethics Inquiry, vol. 11, núm. 1, 2014.

NADimpalli, S. y VenKatachalam, D., "Marketing Reproduction: Assisted Reproductive Technologies and Commercial Surrogacy in India”, Indian Journal of Gender Studies, vol. 23, núm. 1, 2016.

Overall, Ch., "Reproductive Surrogacy and Parental Licensing”, Bioethics, vol. 29, núm. 5, 2015.

PANDE, A., "Commercial Surrogacy in India: Manufacturing a Perfect Mother-Worker”, Signs, vol. 35, núm. 4, 2010.

PRAY, L., "Epigenetics: Genome, Meet Your Environment”, Scientist, 5, julio de 2004.

Reed, K. y Padkocimate, A., The Right Toolkit. Applying Research Methods in the Science of Human Rights, University of California, Berckley, 2012.

Robertson, J., "Legal Change and Stigma in Surrogacy and Abortion", The Journal of Law, Medicine \& Ethics, vol. 43, núm. 2, 2015.

RodrígueZ-Yong, A., y MARTíneZ-MuÑoz, K., "El contrato de maternidad subrogada: la experiencia estadounidense", Revista de Derecho (Valdivia), vol. XXV, núm. 2, 2012.

Ross, Sh., "Diet and DNA Methylation Interactions in Cancer Prevention", Ann NY Acad. Sci., núm. 983, 2003.

Rothstein, M. et al., "The Ghost in Our Genes: Legal and Ethical Implications of Epigenetics", Health Matrix Clavel, 19 (1), 2009.

SÁNCHEZ MORALES, H., "Impactos de la reprogenética en las tendencias demográficas y en las estructuras familiares”, Arbor, vol. 187, 2011.

SANTOS, F. et al., "Evaluation of Epigenetic Marks in Human Embryos Derived from IVF and ICSI", Human Reproduction, vol. 25, núm. 9, 2010.

SARAVAnAN, Sh., "Global Justice, Capabilities Approach and Commercial Surrogacy in India", Medicine, Health care and Philosophy, vol. 18, núm. 3, 2015. 
SCOTTI, L., "La maternidad subrogada en la legislación y jurisprudencia argentina”, Revista Digital En Letra, 2014, disponible en: www.oaji.net.

Shanley, M. L., Making Babies, Making Families. What Matters most in an Age of Reproductive Technologies, Surrogacy, Adoption and Same-Sex and Unsued Parents, Boston, Beacon Press, 2011.

SHETTY, P., "India's Unregulated Surrogacy Industry", The Lancet, vol. 380, núm. 9854, 10 de noviembre de 2012.

SIFRIS, A., "The Family Courts and Parentage of Children Conceived through Overseas Commercial Surrogacy Arrangements: A Child-centred Approach", Journal of Law and Medicine, vol. 23, núm. 2, 2015.

Spar, D., y Harrington, A., "Selling Stem Cell Science: How Markets Drive Law along the Technological Frontier", American Journal of Law and Medicine, vol. 33, núm. 4, 2007.

SpARAGO, A. et al., "Mechanisms Causing Imprinting Defects in Familial Beckwith-Wiedemann Syndrome with Wilms' Tumor”, Human Molecular Genetics, vol. 16, 2007.

STÖGER, R., "The Thrifty Epigenotype: An Acquired and Heritable Predisposition for Obesity and Diabetes?”, Bio Essays, núm. 30, 2008.

Waddington, C., “The Epigenotype”, Endeavour, núm. 1, 1942.

WATERLAND, R. et al., "Maternal Methyl Supplements Increase Offspring DNA Methylation at Axin Fused", Genesis, núm. 44, 2006.

Weidman, J. y JiRTle, R., "Epigenetic Gene Regulation: Linking Early Developmental Environment to Adult Disease", Reproductive Toxicology, núm. 23, 2007.

WilKINSON, S., "The Exploitation Argument against Commercial Surrogacy”, Bioethics, vol. 17, núm. 2, 2003. 